\title{
Recombinant Production and Characterization of an Extracellular Subtilisin-Like Serine Protease from Acinetobacter baumannii of Fermented Food Origin
}

\author{
Nur Syafiqah Muhammed ${ }^{1}$. Nurulfarhana Hussin ${ }^{1}$. Aik Siang Lim ${ }^{1} \cdot$ Mohd Anuar Jonet $^{2} \cdot$ Shaza Eva Mohamad $^{3}$. \\ Haryati Jamaluddin ${ }^{1}$
}

Accepted: 5 April 2021 / Published online: 18 April 2021

(c) The Author(s), under exclusive licence to Springer Science+Business Media, LLC, part of Springer Nature 2021

\begin{abstract}
Acinetobacter baumannii is a ubiquitous bacteria that is increasingly becoming a formidable nosocomial pathogen. Due to its clinical relevance, studies on the bacteria's secretory molecules especially extracellular proteases are of interest primarily in relation to the enzyme's role in virulence. Besides, favorable properties that extracellular proteases possess may be exploited for commercial use thus there is a need to investigate extracellular proteases from Acinetobacter baumannii to gain insights into their catalytic properties. In this study, an extracellular subtilisin-like serine protease from Acinetobacter baumannii designated as SPSFQ that was isolated from fermented food was recombinantly expressed and characterized. The mature catalytically active form of SPSFQ shared a high percentage sequence identity of $99 \%$ to extracellular proteases from clinical isolates of Acinetobacter baumannii and Klebsiella pneumoniae as well as a moderately high percentage identity to other bacterial proteases with known keratinolytic and collagenolytic activity. The homology model of mature SPSFQ revealed its structure is composed of $10 \beta$-strands, $8 \alpha$-helices, and connecting loops resembling a typical architecture of subtilisin-like $\alpha / \beta$ motif. SPSFQ is catalytically active at an optimum temperature of $40{ }^{\circ} \mathrm{C}$ and $\mathrm{pH} 9$. Its activity is stimulated in the presence of $\mathrm{Ca}^{2+}$ and severely inhibited in the presence of PMSF. SPSFQ also displayed the ability to degrade several tissue-associated protein substrates such as keratin, collagen, and fibrin. Accordingly, our study shed light on the catalytic properties of a previously uncharacterized extracellular serine protease from Acinetobacter baumannii that warrants further investigations into its potential role as a virulence factor in pathogenicity and commercial applications.
\end{abstract}

Keywords Acinetobacter baumannii $\cdot$ Subtilisin-like serine protease $\cdot$ S8 peptidase $\cdot$ substrate specificity

\section{Introduction}

$\S$ Nur Syafiqah Muhammed and Nurulfarhana Hussin contributed equally to this work.

Haryati Jamaluddin

haryatijamaluddin@utm.my

Nur Syafiqah Muhammed

nsyafiqah.muhammed@gmail.com

Nurulfarhana Hussin

nfarhana.hussin@gmail.com

Lim Aik Siang

gnaiskiamil@gmail.com

Mohd Anuar Jonet

anuarjonet@nibm.my
Acinetobacter species consist of gram-negative coccobacilli bacteria that are widely occurring in nature with studies showing that the genus can be grown from virtually all soil and surface water samples [1,2]. Acinetobacter species

Shaza Eva Mohamad

shaza@utm.my

1 Department of Bioscience, Faculty of Science, Universiti Teknologi Malaysia, Skudai, Malaysia

2 Structural Biology \& Biophysics Department, Malaysian Genome Institute, Kajang, Selangor, Malaysia

3 Department of Environmental Engineering and Green Technology (EGT), Malaysia Japan International Institute of Technology (MJIIT), Universiti Teknologi Malaysia, Skudai, Malaysia 
have also been detected in food samples of animal and plant origins and have been found to be a natural part of human skin flora [3-5]. However, the most medically significant species, Acinetobacter baumannii was found to rarely occur on human skin under normal circumstances [6,7]. Despite this, Acinetobacter baumannii is increasingly reported to cause nosocomial skin and soft tissue infections which can be fatal [8-10]. Besides that, Acinetobacter baumannii also infects high-risk, immune-compromised patients in intensive care units (ICU) to cause catheter-related bacteremia (bloodstream infection) and ventilator-associated pneumonia $[11,12]$. The ubiquitous nature of Acinetobacter species provides multiple routes by which bacteria from this genus can be introduced into hospital settings [13]. In the past, members from the Acinetobacter genus are considered to be relatively low-grade saprophytes with little clinical significance because up until the early 1970s, nosocomial infections caused by Acinetobacter spp., especially Acinetobacter baumannii could be controlled either with a single or a combination of several commercial antimicrobial drugs [2, 14]. Unfortunately, the impact of uncontrolled usage of antimicrobial drugs caused the emergence of an ever-increasing number of antibiotic resistance pools from numerous countries around the world [15].

Proteases play diverse roles in living organisms and many proteases have the potential for biotechnological applications. Their applications are in the area of food processing, detergent, nutraceutical, and medical industries [16]. Bacterial extracellular proteases especially extracellular serine proteases or ESPs are among the most widely studied of all bacterial enzymes. This is mainly due to their important roles in biological systems thus studying them provides insights into the mechanisms of enzyme action and protein structure-function relationship [17-19]. Furthermore, ESPs have broad substrate specificity which is reflective of their role as scavenging enzymes, and coupled with their relative stability in harsh extracellular environments, they make attractive candidates for potential commercial application. Structurally, ESPs consist of an N terminal secretion signal sequence which is followed by a pro-domain sequence. The signal sequence function to mediate the secretion of the enzyme whilst the pro-domain sequence is autocatalytically cleaved to form the enzyme's mature active conformation $[19,20]$. Aside from their beneficial scientific and commercial roles, extracellular subtilisin proteases can also act as virulence factors in pathogenicity thus, making them viable drug targets for therapeutic agents against diseases [21,22].

There is currently widespread interest in the study of secretory molecules from the Acinetobacter genus especially from Acinetobacter baumannii due to its clinical relevance $[23,24]$. One of the main molecules is extracellular secretory proteases that play diverse essential roles in the interactions of Acinetobacter baumannii with the environment and host tissues. Acinetobacter genus was previously reported to have no extracellular protease activity [25], however recently several clinical isolates have been shown to secrete active proteases that may contribute to virulence [26-30]. On the other hand, proteases from environmental isolates of Acinetobacter can be harnessed for industrial applications but studies on this are limited with only 2 recent significant reports from the past 5 years on proteases from the Acinetobacter genus with potential biotechnological applications [31, 32]. Due to the clinical significance of Acinetobacter baumannii and the ability of ESPs to degrade a wide range of proteinaceous substrates, it is expected that ESPs from Acinetobacter baumannii may display favorable catalytic activities with the potential to be exploited for commercial use. Thus there is a need to characterize the structure and function of new ESPs from Acinetobacter baumannii in order to gain insights into their catalytic activity that may be associated with pathogenicity or have the potential for commercial exploitation.

\section{Materials and Methods}

\subsection{Microorganism and Culture Condition}

The bacterial strain Acinetobacter baumannii TU04 (GenBank: KP204010.1) was isolated from Tapai Ubi, a Malaysian traditional cassava-fermented food [33, 34]. Escherichia coli DH5 $\alpha$ and BL21 (DE3) were employed as hosts for cloning and expression of protease gene, respectively. E. coli strains were grown at $37{ }^{\circ} \mathrm{C}$ in Luria-Bertani (LB) medium supplemented with ampicillin $(100 \mu \mathrm{g} / \mathrm{ml})$ for plasmid selection.

\subsection{Isolation and Identification of SPSFQ Gene}

Genomic DNA was purified from Acinetobacter baumannii TU4 using a Genomic DNA Extraction kit (Promega, USA). A pair of degenerate oligonucleotide primer SerAciB_F: (5'- GGGTTTCATATGATGGCAAATCCTGTAAAT G-3') and SerAciB_R: (5'-GGCCTCGAGTTAAGGAGA TTTATATAACAAGCG-3') corresponding to the extracellular serine protease were designed based on the available genomic database of Acinetobacter strains at the National Centre for Biotechnology Information (NCBI). The PCR reaction solution was prepared by mixing 100-200 ng of bacterial genome DNA as template, $10 \mu \mathrm{M}$ of gene-specific primers each, $2.5 \mathrm{mM}$ dNTPs, $1 \times$ TransTaq HiFi Buffer I, 5U of TransTaq DNA Polymerase High Fidelity (HiFi) (TransGen Biotech, China) and final reaction volume was made to $50 \mu \mathrm{L}$ using the nuclease-free water. The PCR reaction was conducted in an MJ Mini 48-Well Personal Thermal Cycler (Bio-Rad Laboratories, USA) using the following 
thermal profile: an initial denaturation of $5 \mathrm{~min}$ at $94^{\circ} \mathrm{C}$, 35 cycles of denaturation $\left(94{ }^{\circ} \mathrm{C}, 30 \mathrm{~s}\right)$, annealing $\left(55^{\circ} \mathrm{C}\right.$, $30 \mathrm{~s})$, and extension $\left(72{ }^{\circ} \mathrm{C}, 45 \mathrm{~s}\right)$ and a final extension of 5 min at $72^{\circ} \mathrm{C}$. The amplicon was recovered using NucleoSpin ${ }^{\circledR}$ Gel kit (Macherey-Nagel, Germany) prior to ligation into pGEM-T easy vector system (Promega, USA) and transformed into chemically competent $E$. coli $\mathrm{DH} 5 \alpha$ cells. The positive clones were confirmed by colony PCR and sent for nucleotide sequencing service provided by First Base Laboratories, Malaysia. The complete nucleotide sequence was assembled by aligning the forward and reverse strands using BioEdit software before subjected for identification using the nucleotide BLAST algorithm of NCBI [35].

\subsection{Amino Acid Sequence, Phylogenetic and Structural Model Analysis}

Several bioinformatics tools were employed to analyze the nucleotide of the gene encoding SPSFQ. The amino acid translation was done by the Expert Protein Analysis System(ExPASy) Translate tool (http://www.expasy.org) and the active site residues, conserved domains, as well as possible calcium-binding sites, were analyzed by the NCBI's Conserved Domain Database (CDD) https://www.ncbi.nlm. nih.gov/Structure/cdd/wrpsb.cgi) [36, 37]. The phylogenetic tree was built using the protein sequences from the NCBI database bootstrapped with 500 replications in the MEGA version 5.0 software [38]. The information on molecular weight and amino acid composition of SPSFQ was calculated by ExPAsy ProtParam tool (https://web.expasy.org/ protparam/) and potential disulfide linkage was predicted by DiAmino acid Neural Network Application (DiANNA) webserver (http://clavius.bc.edu/ clotelab/DiANNA/) [36, 37, 39]. The Modeller version 9.19 program was employed for homology modeling of SPSFQ protein structure based on the keratinase MtaKer from Meiothermus taiwanensis WR-220 (PDB code: 5WSL_A) and PROCHECK was performed to evaluate the stereochemical quality of the $3 \mathrm{D}$ model structure [40-42]. All graphical images of the SPSFQ model structure were generated using the PyMOL Molecular Graphic System (Schrodinger) [43]. Electrostatic surface analysis of subtilisin S8 proteases was calculated using APBS (Adaptive Poisson-Boltzmann Solver) Electrostatic plugin in Pymol software [43].

\subsection{Expression of Recombinant Protease SPSFQ}

The verified pGEM-SPSFQ sequence was sub-cloned into the expression plasmid, pET-22b (+) using a pair of primers: forward primer (5'-CGC GGA TCC GAT GGC AAA TCC TGT AAA TG-3') reverse primer (5'-CTG CGT CGA CAG GAG ATT TAT ATA ACA AGC G-3') with BamH1 and Sal1 restriction sites incorporated (underlined). The resulting construct was designated as pET-SPSFQ. Confirmation of the positive clones was carried out via colony PCR and nucleotide sequencing. The expression construct $\mathrm{pET}-S P S F Q$ with the correct nucleotide sequence and reading frame was then transformed into the expression host, E. coli BL21 (DE3) for recombinant SPSFQ expression analysis.

A single colony of $E$. coli BL21(DE3) harboring the expression plasmid pET-spsfq was grown in LB broth and incubated at $37{ }^{\circ} \mathrm{C}$ for approximately 18 hours with a shaking speed of $200 \mathrm{rpm}$. The overnight starter culture was diluted 100 -fold into $50 \mathrm{~mL} \mathrm{LB}$ broth containing carbenicillin $(100 \mu \mathrm{g} / \mathrm{mL})$ agitated at $37{ }^{\circ} \mathrm{C}$. Preliminary expression analysis of SPSFQ was induced using a range of isopropyl $\beta$-D-thiogalactoside (IPTG) concentrations: $0.05,0.1$, and $0.2 \mathrm{mmol} / \mathrm{L}$ at $\mathrm{OD}_{600}$ value of 0.6 and incubated at $37{ }^{\circ} \mathrm{C}$. After four hours postinduction, cells were harvested by centrifugation at $10,000 \times g$ and resuspended in cold lysis buffer $(50 \mathrm{mM}$ Tris- $\mathrm{HCl}, \mathrm{pH} 8.0$, and $250 \mathrm{mM} \mathrm{NaCl}$ ). The cells were disrupted by the sonication method and the resulting extract was centrifuged at $12,000 \times \mathrm{g}$ for 20 min under the cold condition to separate soluble cell fraction from the cell pellet. The cell lysates were analyzed on $12 \%$ SDS-PAGE and further confirmation using anti-6x-His mouse monoclonal antibodies (Thermo Scientific, \#MA121315) in the Western blotting.

\subsection{Protein Purification}

Cell-free crude extract from $6 \mathrm{~L}$ culture was applied to a HiTrap HP (GE Healthcare) and eluted using $20 \mathrm{mM}$ Tris-HCl pH 9.0, $300 \mathrm{mM}$ Imidazole, $\mathrm{NaCl} 150 \mathrm{mM}$ at a constantly increasing concentration of imidazole gradient (flow rate of $1.0 \mathrm{~mL} / \mathrm{min}$ ). Fractions containing positive proteolytic activity were pooled for ultrafiltration and buffer exchanged to a low-salt buffer (20 mM Tris- $\mathrm{HCl} \mathrm{pH} 9.0)$ using a regenerated cellulose membrane with a $10 \mathrm{kDa}$ pore size (Amicon Ultra, Millipore) before purification using a HiTrap Q HP anion exchange column. Recombinant SPSFQ was eluted from the HiTrap Q HP column using $20 \mathrm{mM}$ Tris- $\mathrm{HCl}$ pH 9.0, $1 \mathrm{M}$ $\mathrm{NaCl}$ at a constant flow rate of $1.0 \mathrm{~mL} / \mathrm{min}$. Fractions exhibiting protease activities were pooled to be concentrated and buffer-exchanged against low-salt buffer. $100 \%$ glycerol was added into the buffer containing concentrated protease to a final concentration of $20 \%$ glycerol to stabilize the purified recombinant SPSFQ. The sample was then kept at $-20{ }^{\circ} \mathrm{C}$ prior to protease characterization.

\section{Enzyme Assay and Characterization}

\subsection{Caseinolytic Activity Assay}

Five millilitre of $0.65 \%(\mathrm{w} / \mathrm{v})$ casein powder dissolved in $50 \mathrm{mM}$ potassium phosphate buffer $(\mathrm{pH} 8.0)$ and $1 \mathrm{~mL}$ 
of purified recombinant SPSFQ $(0.4 \mu \mathrm{M})$ was incubated at $37{ }^{\circ} \mathrm{C}$ for $30 \mathrm{~min}$. The reaction was stopped with the addition of $5 \mathrm{~mL}$ of $15 \%(\mathrm{w} / \mathrm{v})$ trichloroacetic acid for $30 \mathrm{~min}$ at $37^{\circ} \mathrm{C}$. The reaction mixture was centrifuged at $11,000 \mathrm{~g}$ for $1 \mathrm{~min}$ and $2 \mathrm{~mL}$ of the reaction mixture was transferred into new containers to be incubated with $5 \mathrm{~mL}$ $0.5 \mathrm{M} \mathrm{Na}_{2} \mathrm{CO}_{3}$ and $1 \mathrm{~mL} 50 \mathrm{mM}$ Folic Ciocalteau reagent (Sigma Aldrich; St Louis, MO, USA) for $30 \mathrm{~min}$ at $37{ }^{\circ} \mathrm{C}$. The color change was measured using a spectrophotometer at $660 \mathrm{~nm}$ against blank prepared in the same manner. One unit of proteolytic activity was defined as the amount of enzyme needed to release $1 \mu \mathrm{mol}$ of tyrosine per min under the assay conditions.

\subsection{Effects of Temperature, pH, Metal lons, Protease Inhibitor, Surfactants, Denaturants and Organic Solvent on Recombinant SPSFQ Activity}

The optimum temperature for SPSFQ protease activity was determined by calculating relative activity after assaying $\sim 0.4 \mu \mathrm{M} \mathrm{mL}^{-1}$ of the enzyme at various temperatures ranging from 20 to $60^{\circ} \mathrm{C}$. The relative activity of the enzyme was determined by measuring the amount of tyrosine released underspecified assay conditions and the data were expressed in percentage (\%). A temperature profile of the relative activity versus temperature was constructed by taking enzyme activity at the optimum temperature as $100 \%$. To evaluate the optimum $\mathrm{pH}$, the enzyme activity of the purified protease SPSFQ $\left(\sim 0.4 \mu \mathrm{M} \mathrm{mL}^{-1}\right)$ was measured at $37{ }^{\circ} \mathrm{C}$ under a $\mathrm{pH}$ range of $4.0-11.0$. Casein solutions were prepared using the following buffer system: $50 \mathrm{mM}$ of sodium acetate buffer, $\mathrm{pH} 4.0-5.0$; Tris- $\mathrm{HCl}$ buffer, $\mathrm{pH}$ 6.0-7.0; potassium phosphate, $\mathrm{pH}$ 8.0-9.0 and Glycine- $\mathrm{NaOH}, \mathrm{pH} 10.0-11.0$, respectively.

The effects of metal ions on SPSFQ enzyme activity were studied by pre-incubating the enzyme in the presence of various monovalent $\left(\mathrm{Na}^{+}\right.$and $\left.\mathrm{K}^{+}\right)$and divalent $\left(\mathrm{Mg}^{2+}, \mathrm{Ca}^{2+}, \mathrm{Zn}^{2+}\right.$, and $\left.\mathrm{Cu}^{2+}\right)$ metal ions at a concentration of $5 \mathrm{mM}$ for $30 \mathrm{~min}$ at $37{ }^{\circ} \mathrm{C}$. Recombinant SPSFQ activity was assayed in the presence of protease inhibitors (phenylmethylsulfonyl fluoride (PMSF), ethylenediaminetetraacetic acid (EDTA) and $\beta$-mercaptoethanol) at concentrations of 1 and $5 \mathrm{mM}$; surfactants, and denaturant (urea, sodium dodecyl sulfate (SDS)) at concentrations of 1 and $5 \mathrm{mM}$, Tween-20 at concentrations of $0.5 \%$ and $1.0 \%$, v/vas well as organic solvents (methanol, ethanol, and isopropanol) at a concentration of $5 \%$. The purified SPSFQ enzyme was briefly pre-incubated with selected reagents as mentioned above for $30 \mathrm{~min}$ at $37^{\circ} \mathrm{C}$. The assay was carried out using the caseinolytic assay protocol as described previously. Their relative activities were recorded and expressed in percentage (\%).

\section{Substrate Specificity Assay}

\subsection{Proteolytic Activity on Different Protein Substrates}

The catalytic activity of purified SPSFQ was assayed with various protein substrates: casein, gelatin, fibrin $(0.65 \% \mathrm{w} / \mathrm{v})$ following standard protease assay as explained in Caseinolytic Activity Assay. The catalytic activity towards the simplest substrate, casein was used as control (100\%).

\subsection{Keratinolytic Activity Assay}

Keratinolytic activity of purified SPSFQ was assayed using keratin azure $\mathrm{K} 8500$ as a substrate and by following standard keratinase assay protocol (Sigma Aldrich). The reaction mixture for keratin degradation assay consisted of $20 \mathrm{mg}$ of keratin azure, $4 \mathrm{~mL}$ of $50 \mathrm{mM}$ sodium phosphate solution, and $1 \mathrm{~mL}$ of $1 \mu \mathrm{M}$ of the purified SPSFQ sample. The keratinolytic reaction was incubated at $37^{\circ} \mathrm{C}$ for $1 \mathrm{~h}$ to allow color development. The degradation of the modified substrate was recorded quantitatively by measuring the absorbance at $595 \mathrm{~nm}$, using Proteinase $\mathrm{K}$ as a standard. One unit of keratinolytic activity was defined as the amount of enzyme required to increase absorbance by 0.01 at $595 \mathrm{~nm}$, within $1 \mathrm{~h}$ at $37^{\circ} \mathrm{C}$.

\subsection{Collagenolytic Activity Assay}

Recombinant SPSFQ was assayed for collagenolytic activity with azo dye-impregnated collagen (Sigma \# A4341) as substrate. The reaction mixture for collagen degradation assay consisted of $25 \mathrm{mg}$ of azo dye impregnated collagen, $4 \mathrm{~mL}$ of $0.1 \mathrm{M}$ potassium phosphate solution, and $1 \mathrm{~mL}$ of $1 \mu \mathrm{M}$ purified SPSFQ. The reaction mixture was incubated for $1 \mathrm{~h}$ at $37^{\circ} \mathrm{C}$ under constant shaking. Colour change was recorded quantitatively by measuring the absorbance at $520 \mathrm{~nm}$, using trypsin as a standard. One unit of collagenolytic activity was defined as the amount of enzyme required to increase absorbance by 0.01 at $520 \mathrm{~nm}$, within $1 \mathrm{~h}$ at $37^{\circ} \mathrm{C}$.

\section{Results}

\subsection{Cloning and Sequencing of SPSFQ Gene}

Sequencing of a gene isolated from Acinetobacter baumannii TU04 revealed an 1104-bp nucleotide sequence encoding an open reading frame of 368 amino acid residues (Fig. 1). Sequence analysis using the Blast program against the NCBI 
database indicated that the protein has a high percentage identity of $97-99.5 \%$ to serine protease, an extracellular serine protease, subtilase family protein, and subtilisin-like serine protease of different Acinetobacter strains (Table 1). The phylogenetic analysis clustered the SPSFQ protein in the Acinetobacter clade of subtilisin-like serine proteases group with Acinetobacter baumanni ACICU which is a multidrugresistant clinical strain as its closest neighbor (Fig. 2) [44].

\subsection{SPSFQ Primary Sequence and Domain Analysis}

The NCBI CDD domain analysis divided the deduced SPSFQ amino acid sequence into two major regions, an Inhibitor I9 domain (Q18-D90) and Peptidase S8 domain (A91-P368) (Fig. 1 and 3). These two domains are unique features of serine peptidases grouped under the S8A subfamily of $\mathrm{S} 8$ or often known as the subtilase family in clan SB (subtilisin-like serine protease) based on the classification in the MEROPS database [45]. The inhibitor I9 region or usually termed as pro-domain was found to carry a specific inhibitory activity against the adjacent peptidase S8 domain until it is auto-catalytically cleaved during enzyme maturation [46, 47]. This domain was also found to act as a molecular chaperon to assist the proper folding of mature serine peptidases into their active conformation [48-50]. As the inhibitor I9 domain has an only inhibitory function,
Table 1 BLAST analysis of SPSFQ serine protease from Acinetobacter baumannii TU04

\begin{tabular}{llll}
\hline Identification & Protease type & $\begin{array}{l}\text { Amino } \\
\text { acid iden- } \\
\text { tities }\end{array}$ & Identity (\%) \\
\hline Serine protease & Serine & $367 / 368$ & 99.5 \\
$\begin{array}{l}\text { Extracellular serine pro- } \\
\text { teinase }\end{array}$ & Serine & $364 / 368$ & 98.9 \\
$\begin{array}{l}\text { Subtilase family protein } \\
\begin{array}{l}\text { Subtilisin-like serine } \\
\text { protease }\end{array}\end{array}$ & Serine & $363 / 368$ & 98.6 \\
$\begin{array}{l}\text { Alkaline serine exopro- } \\
\text { tease A }\end{array}$ & Serine & $363 / 368$ & 98.6 \\
\hline
\end{tabular}

consequently in this study, amino acid multiple sequence alignment analysis and homology modeling studies were focused mainly on the catalytically relevant Peptidase S8 domain. Multiple sequence alignment of SPSFQ amino acid was performed against a protease from a clinical isolate, Acinetobacter baumannii strain 1656-2, and closely related serine proteases from other bacteria with known Inhibitor I9 and Peptidase S8 domains and percentage amino acid identity range of between 38 and $99 \%$ to SPSFQ (Table 2).

The amino acids of the peptidase S8 region of SPSFQ contained conserved features as highlighted in the multiple

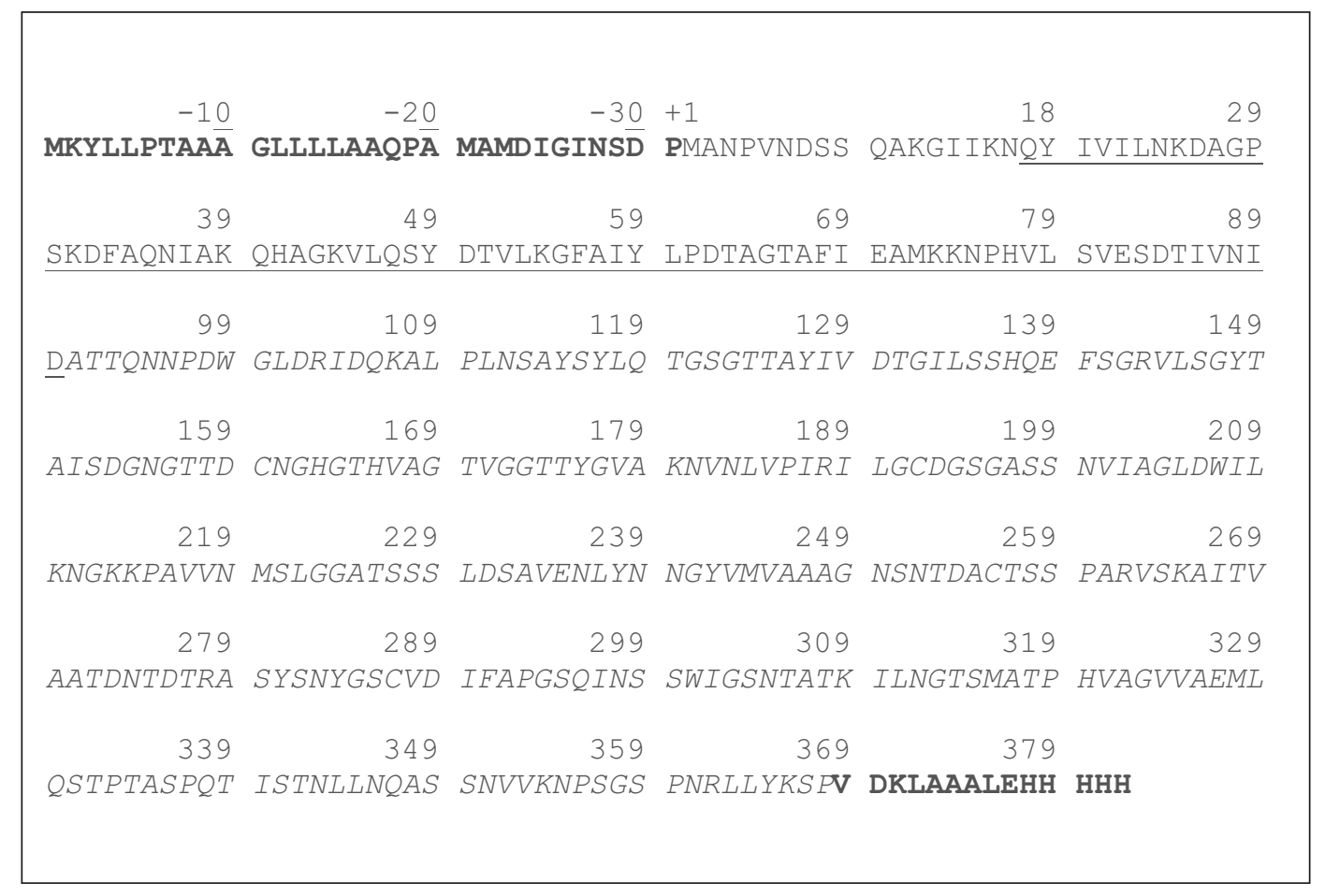

Fig. 1 The amino acid sequence of the cloned SPSFQ from Acinetobacter baumannii TU04. The predicted inhibitor 19 domain $(\mathrm{Q} 18$ D90) and adjacent Peptidase_S8 domain (A91-P368) are labeled as underlined and in italic, respectively. The $\mathrm{N}$-terminal and C-terminal expression vector cassette are labeled in bold 


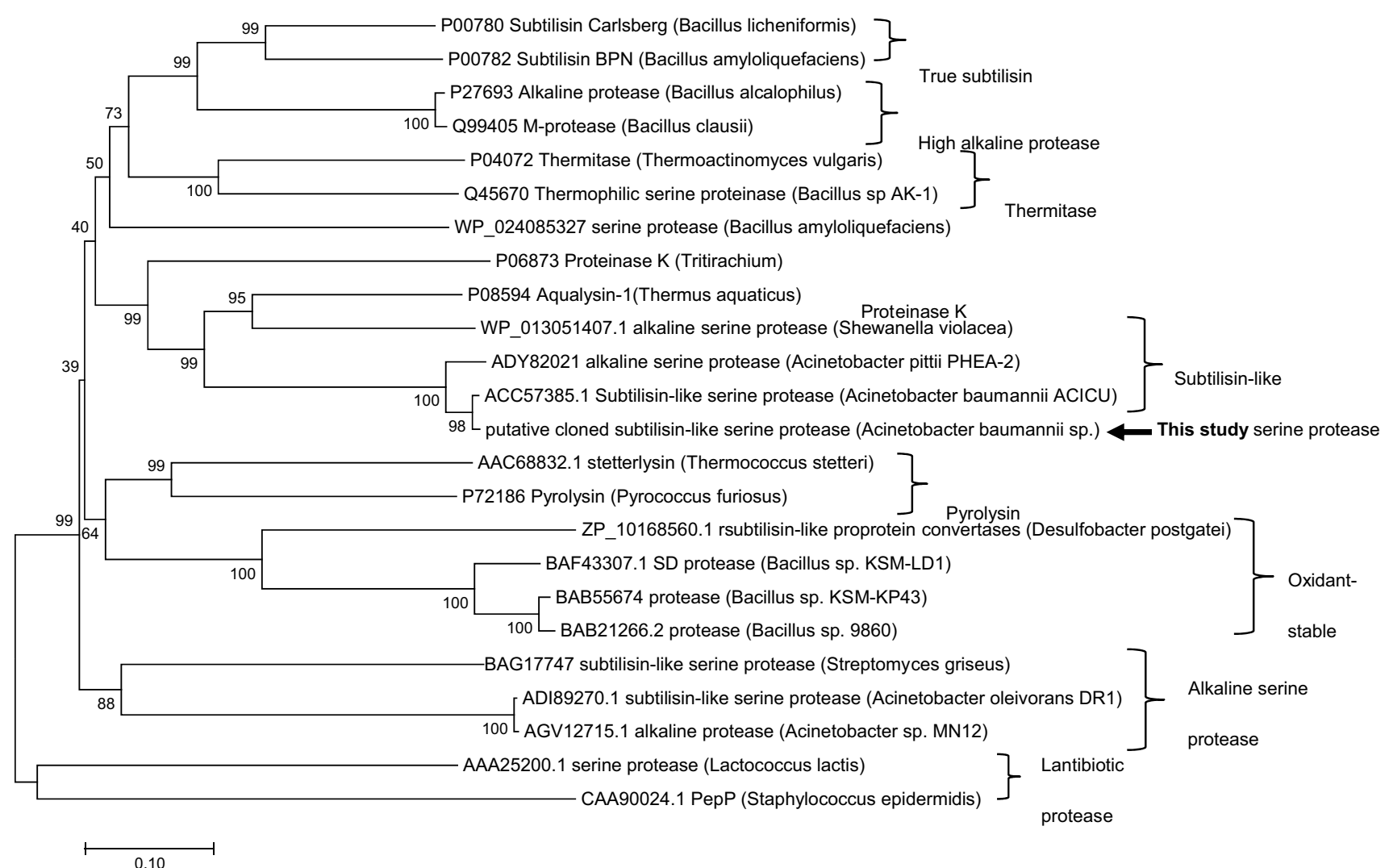

Fig. 2 Phylogenetic tree of SPSFQ from Acinetobacter baumannii TU04 based on protein sequence representing different clusters of protease family. The evolutionary analysis was conducted by using MEGA version 5.0 software

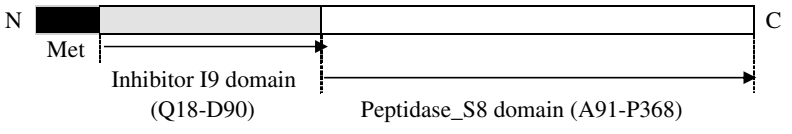

Fig. 3 Schematic diagram of predictive domain structure of SPSFQ represents the position of $\mathrm{N}$-terminal Inhibitor I9 and Peptidase_S8 sequence alignment (Fig. 4). The catalytic triad consisting of Asp40, His 73, and Ser225 and a catalytic subsite, Asn160 termed as an oxyanion hole of SPSFQ are well aligned with other proteases. Based on the catalytic mechanism of serine peptidases, the hydroxyl group of catalytic Ser225 serves as a catalytic nucleophile to attack the scissile peptide bond of the substrate while His73 acts as proton donor and acceptor, and Asp40 is believed to assist in the proper orientation of His imidazole ring during the process $[51,52]$. The
Table 2 Comparison of amino acid sequence of mature SPSFQ with other serine proteases from bacteria and fungi are generated using Clustal Omega identity matrix analysis

\begin{tabular}{|c|c|c|c|c|c|c|c|c|}
\hline & \multicolumn{8}{|c|}{ Identity $(\%)$} \\
\hline & 1 & 2 & 3 & 4 & 5 & 6 & 7 & 8 \\
\hline 1. SPSFQ Acinetobacter baumannii TU4 & 100 & 99.3 & 99.3 & 59.9 & 47.3 & 42.3 & 40.5 & 38.2 \\
\hline $\begin{array}{l}\text { 2. Extracellular serine protease Acinetobacter bau- } \\
\text { mannii 1656-2 (ADX04172) }\end{array}$ & & 100 & 100 & 59.9 & 48.0 & 42.4 & 40.9 & 38.6 \\
\hline $\begin{array}{l}\text { 3. Extracellular serine protease Klebsiella pneumo- } \\
\text { niae (SSW74921) }\end{array}$ & & & 100 & 59.9 & 48.0 & 42.4 & 40.9 & 38.6 \\
\hline 4. Keratinase Meiothermus taiwanensis WR-220 & & & & 100 & 49.8 & 47.1 & 45.9 & 44.4 \\
\hline $\begin{array}{l}\text { 5. Destructin-1 } \\
\text { Pseudogymnoascus destructans }\end{array}$ & & & & & 100 & 53.7 & 51.8 & 54.7 \\
\hline 6. Proteinase K Tritirachium album Limber & & & & & & 100 & 62.0 & 65.1 \\
\hline 7. Cuticle-degrading PL646 Paecilomyces Lilacinus & & & & & & & 100 & 72.0 \\
\hline 8. Cuticle-degrading Ver112 Verticillium Psalliotae & & & & & & & & 100 \\
\hline
\end{tabular}



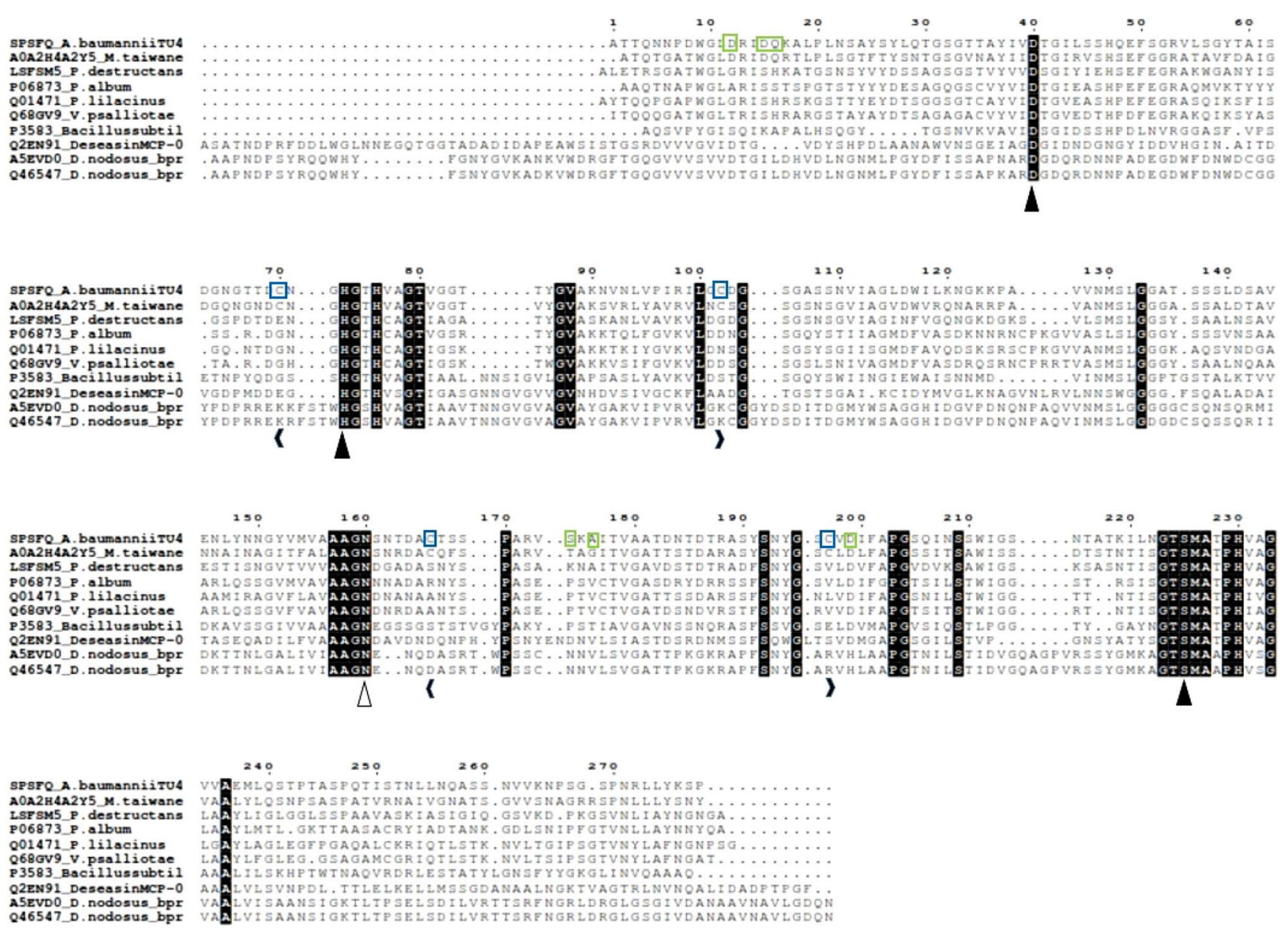

Fig. 4 Comparative amino acid alignment of SPSFQ with subtilisinlike serine proteases from different organisms: Meiothermus taiwanensis Wr-220 (A0A2H4A2Y5); Pseudogymnoascus destructans (LSFSM5); Parengyodontium album (P06873); Paecilomyces lilacinus, PL646 (Q01471), Verticillium psalliotae, Ver112 (Q68GV9); fibrin-degrading nattokinase from Bacillus subtilis (P3583); marine Pseudoalteromonas sp (Q2EN91); Dichelobacter nodosus (A5EVD0 and Q46547). The regions of amino acids with black background

stabilization of tetrahedral intermediate generated during the reaction steps is contributed by Asn 160 by forming a structural component of oxyanion hole with catalytic serine [52]. The presence of catalytic triad residues in the order of Asp-His-Ser and Asn to form the oxyanion hole is conserved within the S8 subfamily yet different from the S53 subfamily although they are grouped under the same clan SB of serine peptidases [45, 52]. The SPSFQ sequence is likely to contain two calcium-coordination sites at positions Asp12, Asp15, Gln16, and Ser174, Ala176, Asp199 respectively (Fig. 4). In the peptidases S8 subfamily, the binding of calcium ion to one or more calcium-binding sites in the enzyme molecule is essential for correct folding and structure stability besides enhancing the thermal stability of the proteases which contribute to their resistance against proteolysis, either by itself or by other proteases $[42,53,54]$. and white foreground are completely conserved.The catalytic triad Asp40, His73, Ser225 and oxyanion hole Asn160 (SPSFQ numbering) are highlighted with black and open circle, respectively. The cysteine pairs participated in the disulphide bridge are marked with $<$ and $>(<$ Cys70-Cys102 $>$ and $<$ Cys166-Cys197 $>)$. The predicted calcium-binding sites for SPSFQ are also highlighted in green boxes. The illustration is generated by ESPript (http://espript.ibcp.fr) [84]

\subsection{D Structure of SPSFQ Model}

In order to further understand the catalytic properties of the active form of SPSFQ, we generated a structural model of SPSFQ without the Inhibitor I9 region. Based on known 3D structures extracted from Protein Databank Database (PDB), SPSFQ (A91-P368) showed a percentage sequence identity of $61 \%$ to a thermophilic keratinase from $M$. taiwanensis WR-220, MtKer (PDB code: 5WSL) that was then selected as the template for homology modeling [42].

The resulting homology model of SPSFQ was evaluated for its quality utilizing several model evaluation servers (Table 3). First, the Phi/Psi Ramachandran plot of the PROCHECK tool was used to assess the backbone phi and psi dihedral angles of the model [55]. PROCHECK analysis results showed that $97.8 \%$ of residues from the model 
Table 3 Model evaluation summary using different tools

\begin{tabular}{llcc}
\hline Model evaluation tool & Evaluation scheme & $\begin{array}{c}\text { Score result (\%) } \\
\text { Normal range } \\
\text { of the score } \\
(\%)\end{array}$ \\
\hline PROCHECK & $\begin{array}{l}\text { The number of amino acids in the allowed region based on Psi/Phi } \\
\text { Ramachandran Plot }\end{array}$ & 97.8 & $>90$ \\
VERIFY3D & The number of amino acids having an average 3D-1D score above 0.2 & 100 & $>80$ \\
ERRAT & The overall quality for nonbonded atomic interactions & 90.1 & $>50$
\end{tabular}

were scored in the favored and allowed region indicating a good stereo-chemical quality of the model. Similar results were achieved when the SPSFQ model was analyzed using VERIFY3D which showed that $100 \%$ of residues displayed an average $3 \mathrm{D}-1 \mathrm{D}$ score above 0.2 , beyond the satisfactory score of $80 \%$ [56, 57]. The overall quality for nonbonded atomic interactions of the SPSFQ model was also evaluated by the ERRAT program by comparing the statistics of the SPSFQ model with that of highly refined structures [58]. An ERRAT score of $90.1 \%$ was achieved which is greater than the acceptable score of $50 \%$. These structure validation analyses indicated that the SPSFQ homology model is of good quality and reliable, meeting the standard protein structure stereo-chemical geometry requirements.

The structural features of the model are composed of 10 $\beta$-strands, $8 \alpha$-helices and connecting loops resembling a typical architecture of subtilisin-like $\alpha / \beta$ domain with parallel $\beta$ sheets occupying the central region of the structure, sandwiched between two layers of $\alpha$ helices (Fig. 5) [59, 60]. Two calcium ions, as well as two disulfide bridges were found associated with the structure of the model template, MtKer (5WSL) [42] and this correlated with the positions of amino acids predicted to occupy the calcium-binding sites and amino acids predicted to form disulfide bridges in the SPSFQ model (Fig. 5). The superposition between SPSFQ and 5WSL with a close-up view of the catalytic triad and oxyanion hole residues is illustrated in Fig. 6. This highly identical geometrical arrangement of catalytic triad AspHis-Ser in the $\alpha / \beta$-elements of the protein structure served as a distinct feature of SPSFQ as a new member that falls under the S8 subfamily (subtilase) of the subtilisin-like serine protease superfamily $[45,51]$.

\subsection{Recombinant Expression and Purification of Recombinant SPSFQ}

Bioinformatics analysis indicated that the SPSFQ sequence consists of two major domains; the N-terminal inhibitor I9 (pro-domain) and peptidase S8 domain carrying the conserved catalytic triad of Asp-His-Ser that belongs to the S8A subfamily peptidases. To investigate whether these domains exhibited functional characteristics of a serine protease, an expression plasmid of SPSFQ was constructed in a pET22b

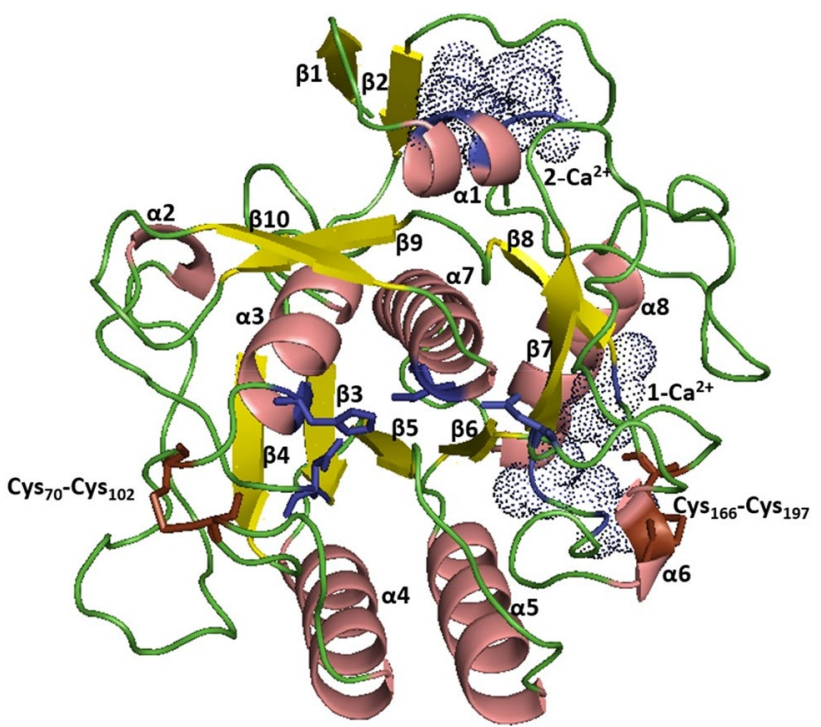

Fig. 5 Ribbon-plot representation of the secondary elements and theoretical tertiary structure of the S 8 domain of SPSFQ. The $\alpha$ helices, $\beta$ strands and loops are colored salmon red, yellow and green, respectively. Side chains of the catalytic triad (Asp40-His73-Ser225) and Asn 160 are shown as blue sticks. The predicted primary and secondary $\mathrm{Ca} 2+$ binding site are rendered in blue dotted surface. The potential cysteine pairs for disulphide bridge are shown as brown sticks

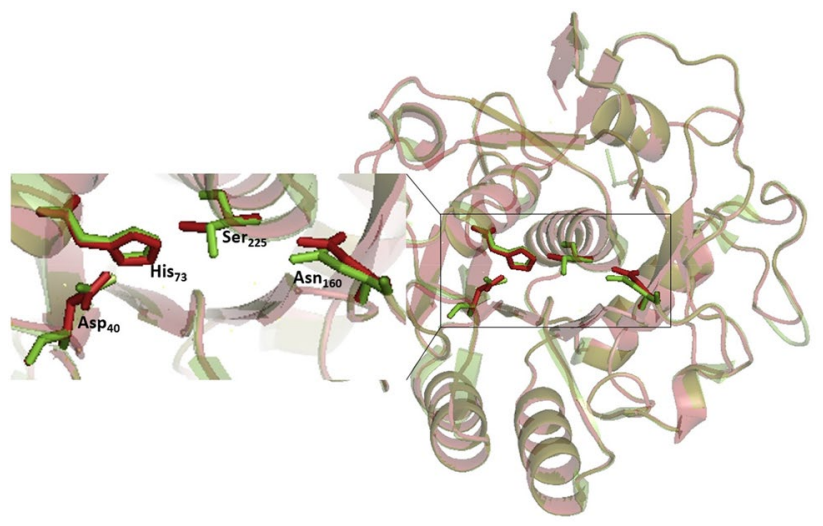

Fig. 6 Superposition of SPSFQ (red) and its template, 5WSL (green), and a close-up view of the catalytic triad and oxyanion hole (SPSFQ numbering) (color figure online) 
vector containing both $\mathrm{N}$-terminal pro-domain and peptidase $\mathrm{S} 8$ domain linked by a C-terminal $6 x$ His-tag for recombinant expression in $E$. coli system with a calculated molecular weight at 42,897 Da.

During preliminary expression analysis of IPTG-induced crude lysates, the apparent molecular weight of recombinant SPSFQ was determined to be approximately $30 \mathrm{kDa}$ when immunoblotted with 6xHis tagged mouse monoclonal antibodies (Fig. 7a). Compared to uninduced cell lysates, only the IPTG-induced samples showed the proteolytic ability by digesting the $1 \%$ casein and skimmed milk substrates (Fig. 7b and c) which indicated the presence of recombinant protease activity. The discrepancy of the size observed here might due to the occurrence of autocatalytic processing of $\mathrm{N}$-terminal inhibitor $\mathrm{I} 9$ domain with an approximate size of $12.8 \mathrm{kDa}$ (based on amino acid sequence prediction) that was cloned together during the construction of SPSFQ expression plasmid (Fig. 1). The subtilisin family members of bacterial extracellular serine proteases shared similar $\mathrm{N}$-terminal primary structure characteristics containing the pro-domain which on cleavage, assist in the folding of the adjacent catalytic peptidase domain to its mature active conformation $[17,18,61]$.

\subsection{Purification of Recombinant SPSFQ}

Crude extract from twelve gram of cell biomass was initially purified on a HiTrap HP column and SPSFQ eluted at an imidazole concentration of 100-150 mM. Further purification was successfully carried out on a Q-sepharose column and SPSFQ was eluted at $\mathrm{NaCl}$ concentrations of 579 to
$683 \mathrm{mM}$. The purified SPSFQ was concentrated further using a Vivaspin centrifugal filter with a molecular weight cut-off of $10 \mathrm{kDa}$ and this yielded pure SPSFQ at a final concentration of $1.18 \mathrm{mg} / \mathrm{mL}$. A typical purification table for purification of SPSFQ is presented in Table 4 and the SDS-PAGE image of the purified SPSFQ is shown in Fig. 8.

\subsection{Characterization of Purified SPSFQ}

In order to further understand the catalytic properties of SPSFQ, physicochemical parameters for SPSFQ activity were characterized. SPSFQ remained catalytically active over a range of temperatures varying from 20 to $70{ }^{\circ} \mathrm{C}$, at $\mathrm{pH}$ 8. The optimum reaction temperature for SPSFQ was observed at $40{ }^{\circ} \mathrm{C}$, above which the activity began to decline sharply where it almost halved at $50{ }^{\circ} \mathrm{C}$, further decreased to almost $15 \%$ at $60{ }^{\circ} \mathrm{C}$ and was almost completely abolished at $70{ }^{\circ} \mathrm{C}$ (Fig. 9). There was a steady increase in SPSFQ activity from $\mathrm{pH} 4-8$ and the activity peaked at $\mathrm{pH} 9(100 \%)$ however, a further increase in $\mathrm{pH}$ beyond 9 decreased the enzymatic activity (Fig. 10). The influence of metal ions on protease activity is summarized in Fig. 11. Some metal ions are believed to have a stimulatory or inhibitory effect on enzyme activity. The metal ions tested did not significantly show any appreciable inhibitory effects as they caused only a minimal decrease in SPSFQ enzyme activity.

The effects of protease inhibitors; PMSF, EDTA, urea, and 2-mercaptoethanol at concentrations of 1 and $5 \mathrm{mM}$ on enzyme activity were also investigated. While EDTA (metalloprotease inhibitor) and 2-mercaptoethanol had no significant inhibitory effects on the proteolytic activity of SPSFQ,

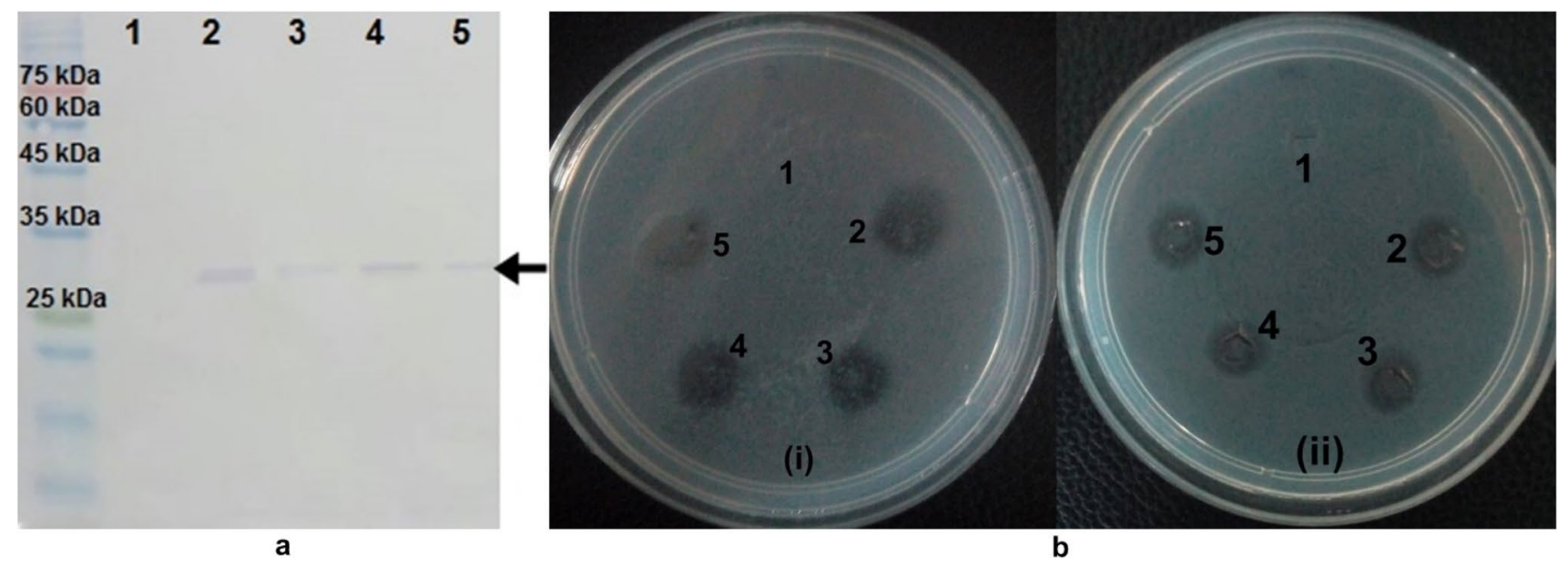

Fig. 7 Analysis of SPSFQ expression at $37{ }^{\circ} \mathrm{C}$ with different IPTG concentrations. a Confirmation of 6x-His tagged recombinant SPSFQ by immunoblotting analysis. Lanes 1- uninduced BL21 (DE3) host, 2- uninduced SPSFQ, 3 to 5- induced SPSFQ at 0.05, 0.1, $0.2 \mathrm{mM}$ IPTG, respectively. b Paper disc-agar diffusion assay for protease activity. Disc filter papers were infused with equal volume $(20 \mu \mathrm{l})$ of crude cell lysates and placed on agar plate containing $1 \%$ of different protein substrates (i) casein (ii) skim milk. For better demonstration of protease activities, the disc papers were removed after overnight incubation at $37^{\circ} \mathrm{C}$. The disc positions are labeled 1- uninduced BL21 (DE3) host, 2- uninduced SPSFQ, 3 to 5- induced SPSFQ at $0.05,0.1,0.2 \mathrm{mM}$ IPTG, respectively (color figure online) 
Table 4 Purification summary of recombinant SPSFQ from Acinetobacter baumannii TU04 (SPSFQ)

\begin{tabular}{lccccc}
\hline Procedure & Total protein (mg) & Total activity (U) & $\begin{array}{l}\text { Specific } \\
\text { activity (U/ } \\
\text { mg) }\end{array}$ & Purification (fold) & Yield (\%) \\
\hline Crude Lysate & 4807.2 & $17,120.09$ & 3.56 & 1 & 100 \\
HiTrap HP & 10.29 & 1105.62 & 107.45 & 30.170 & 6.458 \\
Q Sepharose & 2.43 & 461.52 & 189.93 & 53.330 & 2.696 \\
Vivaspin 10 kDa & 2.08 & 469.26 & 225.33 & 63.272 & 2.741 \\
\hline
\end{tabular}

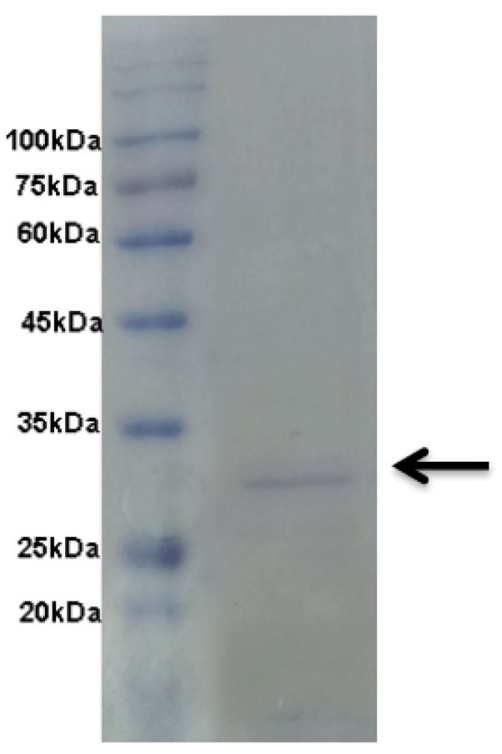

Fig. 8 12\% SDS page gel of purified SPSFQ. Lane 1: Protein marker; Lane 2: SPSFQ protein band after anion exchange chromatography purification (indicated with arrow) (color figure online)

1 and $5 \mathrm{mM}$ PMSF (serine protease inhibitor) caused a significant reduction to SPSFQ activity by approximately $74 \%$ and $99 \%$, respectively (Fig. 12). The effect of 1 and $5 \mathrm{mM}$ of the anionic detergent SDS and $0.5 \%$ and $1 \%$ of the non-ionic detergent Tween 20 on enzyme activity is shown in Fig. 12.
Interestingly, a low concentration of urea $(5 \mathrm{mM})$ is enough to distort the structural integrity of SPSFQ, thus exhibiting a significantly lower relative activity of $17.71 \%$. Relative activities recorded by other inhibitors are also summarized in Fig. 12. Although ionic surfactants (cationic and anionic) were reported to disrupt the structural integrity of most proteases, SPSFQ was observed to be able to retain 90.25 and $87.78 \%$ activity after incubation with $1 \mathrm{mM}$ and $5 \mathrm{mM}$ of SDS respectively at $37^{\circ} \mathrm{C}$ for $30 \mathrm{~min}$. However, 0.5 and $1.0 \%$ Tween-20 (non-ionic surfactants) conferred mild inhibitory effects to the enzyme with a reduction of the enzyme activity to $79 \%$ and $86.34 \%$, respectively.

One of the crucial features of secreted serine protease is that the enzymes have evolved to confer broad substrate preference in order to accommodate versatile biological roles in the external environment. Thus, it is expected for extracellular proteases to be able to hydrolyze more than one proteinaceous substrates albeit with varying degrees of specificity. Furthermore, primary sequence analysis showed that SPSFQ shared moderately high amino acid similarity to other reported bacterial proteases that conferred catalytic activity towards tissue-associated protein components. Therefore, the enzymatic activities of SPSFQ on casein and other tissue-associated proteinaceous substrates such as gelatin (denatured collagen), keratin, collagen, and fibrin were assayed. Results presented in Table 5 indicated that besides casein, purified SPSFQ was able to hydrolyze a
Fig. 9 Influence of temperature on the activity of purified SPSFQ from Acinetobacter baumannii TU04. Protease assay was carried out at various temperatures $\left(20\right.$ to $\left.70{ }^{\circ} \mathrm{C}\right)$ for $30 \mathrm{~min}$ at $\mathrm{pH} 8$. Mean values are plotted with error bar representing the mean standard deviation of triplicates in each individual experiment (color figure online)

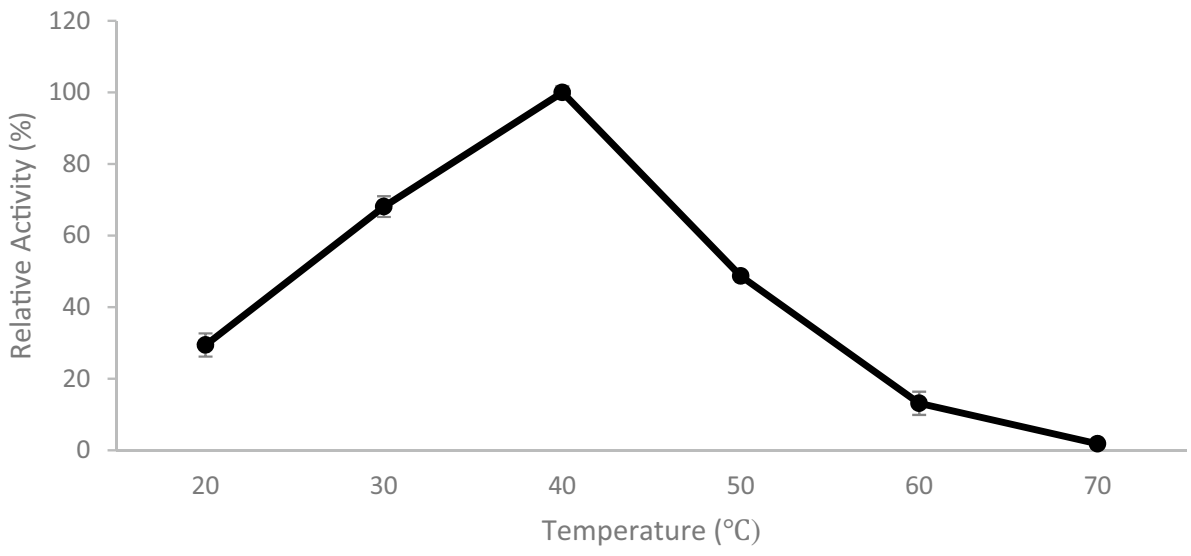



activity of purified SPSFQ from Acinetobacter baumannii TU04. Protease assay was carried out at various $\mathrm{pH}(4-11)$, for with error bar representing the mean standard deviation of triplicates in each individual experiment (color figure online)
Fig. 10 Influence of $\mathrm{pH}$ on the $30 \mathrm{~min}$. Mean values are plotted

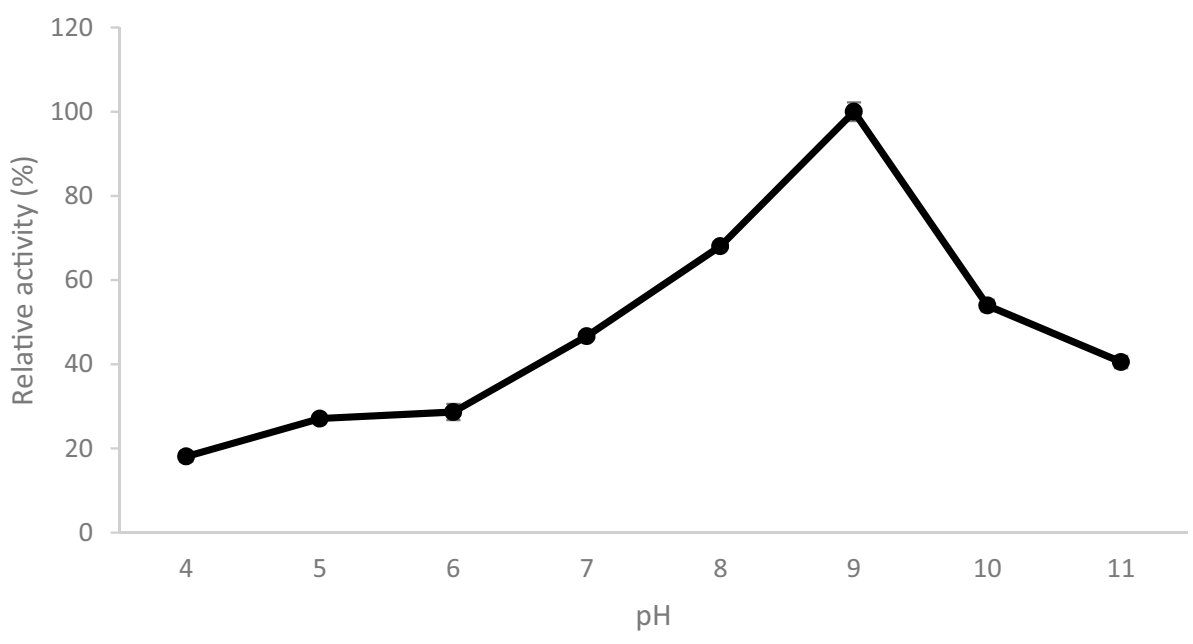

variety of natural/modified complex protein substrates i.e. denatured collagen (gelatin), fibrin, azure keratin, and azocoll (azo dye-impregnated collagen). The highest SPSFQ activity was observed for casein at $92 \mathrm{U} / \mathrm{mL}$ followed by to a much lesser degree; gelatin and azure keratin with activity values of $15.871 \mathrm{U} / \mathrm{mL}$ and $9.375 \mathrm{U} / \mathrm{mL}$ respectively. SPSFQ showed low catalytic activity towards fibrin $(1.089 \mathrm{U} / \mathrm{mL})$ and Azocoll (0.037 U/mL).

\section{Discussion}

Fig. 11 Influence of metal ions on the activity of purified SPSFQ from Acinetobacter baumannii TU04. Protease assay was carried out by pre-incubated reaction mix with several metal ions for $30 \mathrm{~min}$. Mean values are plotted with error bar representing the mean standard deviation of triplicates in each individual experiment (color figure online)
Amino acid sequence and domain analysis of SPSFQ indicated that SPSFQ is a serine protease grouped under the S8 subfamily of clan SB (subtilisin-like serine protease). This is further reinforced by the structural analysis of the SPSFQ model that showed identical amino acid and geometrical arrangement of important catalytic sites to its homology
Fig. 12 Influence of various reagents on activity of the purified recombinant protease from Acinetobacter baumannii TU04. Mean values are plotted with error bar representing the mean standard deviation of triplicate in each individual experiment (color figure online)

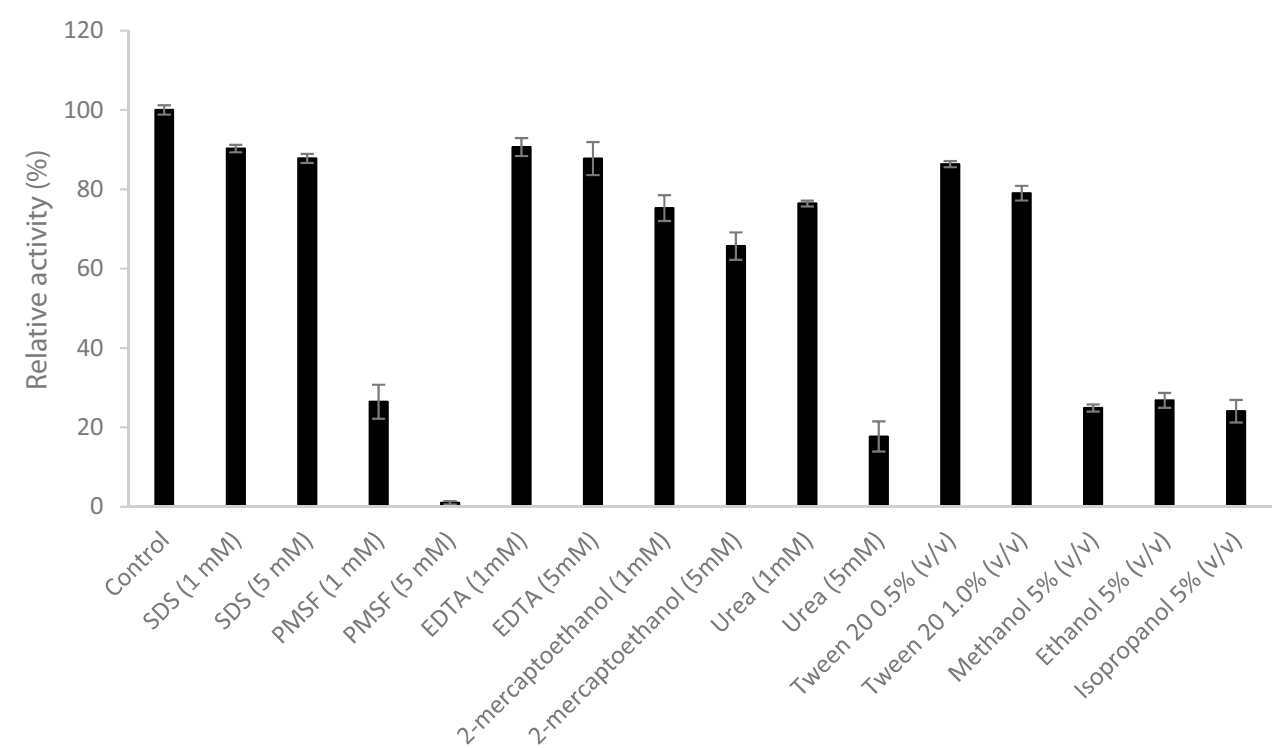


Table 5 Substrate specificity profile of the purified SPSFQ from Acinetobacter baumannii TU04

\begin{tabular}{llll}
\hline Substrate & $\begin{array}{l}\text { Concentration } \\
(\mathrm{w} / \mathrm{v})(\%)\end{array}$ & $\begin{array}{l}\text { Monitoring } \\
\text { wavelength } \\
(\mathrm{nm})\end{array}$ & $\begin{array}{l}\text { Activity } \\
\text { enzyme }(\mathrm{U} / \\
\mathrm{mL})\end{array}$ \\
\hline $\begin{array}{l}\text { Natural substrate } \\
\text { Casein }\end{array}$ & 0.65 & 660 & 92.304 \\
Gelatin & 0.65 & 660 & 15.871 \\
Fibrin & 0.65 & 660 & 1.089 \\
Modified substrate & & & \\
Azure Keratine & 0.44 & 595 & 9.375 \\
Azocoll & 0.49 & 520 & 0.037 \\
\hline
\end{tabular}

modeling template, 5WSL which is also a protease from the peptidase S8 subfamily. The amino acid sequence and structural features observed in both SPSFQ and MtKer crystal structure (5WSL) were unique to the peptidase 8 subfamily. Both enzymes displayed two calcium ion binding sites which are crucial for the correct folding and structural stability of the enzymes. SPSFQ also displayed two predicted disulfide bridges at identical sites to that of MtKer structure (5WSL). Previous studies on peptidases have shown that disulfide bonds can increase thermal stability and breaking the disulfides with reducing agents lead to inactivation as well as a significant reduction in the thermostability of the enzymes $[42,62,63]$.

Further analysis of SPSFQ amino acid sequence homology showed that it shared the highest percentage identity of $99 \%$ to extracellular serine proteases from clinical isolates, Acinetobacter baumannii 1656-2 (ADX04172) and Klebsiella pneumoniae (SSW74921); followed by 59.9\% sequence identity to keratinase from Meiothermus taiwanesis (MtKer) and 47.3\% to Destructin-1 from Pseudogymnoascus destructans. Acinetobacter baumannii 1656-2 is a medically relevant strain that was shown to produce sturdy biofilm and has multiple-drug resistance [64]. Interestingly, SPSFQ was also shown to be almost identical to an extracellular serine protease from another pathogenic bacteria, Klebsiella pneumoniae. Acinetobacter baumannii and Klebsiella pnuemoniae are both nosocomial pathogens that can cause ventilator-associated pneumonia and sepsis [65]. More interestingly, both bacteria were reported to cause dual infection in patients with multiple comorbidities where the two strains were reported to grow entwined in a colony presented as a single morphology that required repeated cultures to separate [66]. However, the functional properties of the two proteases could not be compared further as the protease from Klebsiella pnuemoniae has not been characterized.

MtKer and Desctructin-1 are both proteases with the ability to degrade mammalian structural proteins that are the main components of tissues and skin i.e.; keratin and collagen respectively. In particular, Destructin-1 is the enzyme implicated in the white-nose disease that affects bats in North America. The enzyme that is secreted by the psychrophilic fungus, Pseudogymnoascus destructans causes extensive damage in the subcutaneous tissues which results in ulcerative necrosis and tissue destruction [67]. The recombinant form of keratinase from Meiothermus taiwanesis (MtKer) possessed keratinolytic activities at temperatures ranging from 25 to $75^{\circ} \mathrm{C}$ and $\mathrm{pH}$ from 4 to 11 , with a maximum keratinolytic activity at $65^{\circ} \mathrm{C}$ and $\mathrm{pH} 10$ [42]. $\mathrm{Wu}$ and co-workers proposed that keratinase activity of a protease can be predicted based on overall structural similarity to the crystal structure of MtKer (5WSL) and went on to prove their hypothesis by successfully showing that two proteins with similar structural fold to MtKer, aqualysin I from T. aquaticus YT1 and peptidase from D. radiodurans $\mathrm{R} 1$ both possessed strong keratinase activity despite having only moderately high sequence identity of $59.7 \%$ and $53.7 \%$ respectively to MtKer [42].

Recombinant SPSFQ was expressed as an active $30 \mathrm{kDa}$ protein which is smaller than the calculated molecular weight of $42,897 \mathrm{Da}$. This result was similar to that of a recombinant alkaline serine protease isolated from Acinetobacter $\mathrm{sp}$. IHBB B 5011 (MN12) was expressed as a $35 \mathrm{kDa}$ biologically active protease upon maturation of its larger precursor protein that had a molecular weight of $50 \mathrm{kDa}$ [31]. It has been well-documented that extracellular subtilisin-like proteolytic enzymes of the S8A subfamily are initially synthesized as an intermediate precursor before undergoing activation by intramolecular auto-proteolysis of its pro-peptide to form the mature and active protease [42, $46,51,68,69]$. SPSFQ showed optimum activity at $\mathrm{pH} 9$ in accordance with other previously reported serine proteases that mostly displayed optimum activity at neutral to alkaline $\mathrm{pH}$ [70]. The addition of $\mathrm{Ca}^{2+}$ and $\mathrm{Mg}^{2+}$ showed stimulatory effects on SPSFQ activity and this reflected similar results from other serine proteases from bacteria such as Geobacillus toebii and Geobacillus sp. YMTC 1049 [71]. Susceptibility to the inhibitory effect of PMSF displayed by SPSFQ also confirmed that it is a serine protease as PMSF is generally known to confer irreversible inhibition effects on serine proteases by sulphonating the reactive serine residue of a protease thus, suppressing the catalytic activity of the enzyme [72]. SPSFQ also showed catalytic stability in the presence of sodium dodecyl sulphate (SDS) which is a surfactant often used in detergents and cleaning agents. This coupled with its optimum activity under alkaline $\mathrm{pH}$ indicates the potential application in detergents like many other reported extracellular subtilisins [73, 74].

SPSFQ showed varying degrees of catalytic activities towards different protein substrates. The enzyme showed the highest activity towards casein but much lower activities for more complex substrates such as gelatin, azure keratin, fibrin, and azo-collagen. The varying degree to which 
SPSFQ was able to degrade tissue-associated protein substrates may be explained by the properties of protein substrates, including hydrophobicity and surface charge which are two factors influential in determining the catalytic efficiency of proteases $[54,75]$. Liu and co-workers described the association between electrostatic surface potential of cuticle-degrading proteases with diffusion and adsorption efficiency of the enzymes toward the negatively charged cuticles $[54,76]$. In order to investigate this further, comparison of the electrostatic surface potential of the SPSFQ model with several other crystal structures and 3D models of subtilisin S8 enzymes that had been shown to have strong degrading capabilities for either keratin, fibrin, collagen, cuticle, or extracellular matrices (ECM) such as fibronectin, insoluble elastin, and hoof materials was conducted [42, 67, 75, 77, 78]. In Fig. 13a, the substrate-binding cleft of SPSFQ showed uniform distribution of positive and negative charges, with the less neutral region. This is different from the keratin degrader, MtKer (Fig. 13b) which showed a more neutral region with some patches of negative and positive charges at the substrate-binding cleft. Interestingly, a predominantly negative charge on substrate-binding cleft can be observed in increasing order for proteases degrading the following substrates: fibrin (Fig. 13c), ECM (Fig. 13i), cuticle (Fig. 13d and e) and collagen (Fig. 13g and h). Several reports also emphasized that the key properties of selectivity in proteolytic cleavage by subtilisin-like proteases are determined by the nature of residues occupying the $\mathrm{S} 1$ substrate binding cleft $[54,75,77-80]$. Sequence alignment of subtilisins in complex with either inhibitor, pro-peptide, or peptide fragments indicated that the small, neutral amino acid serine at position 161 in SPSFQ may compromise its ability to degrade collagen and fibrin because proteases that can degrade those substrates have charged amino acids Asp or Glu at the same positions in the S1 substrate binding cleft (Fig. 14).

Other subtilisin S8 proteases including keratinase from Meiothermus taiwanensis WR-220, proteinase K from Tritirachium album, cuticle-degrading enzymes from P. lilacinus and L.psalliotae were reported to exhibit high catalytic activity towards their respective proteinaceous substrates; keratin, cuticle extract, and collagen, but at a higher optimum temperature between 50 and $65{ }^{\circ} \mathrm{C}[42,77]$. These observations correlated with the enzymes' structures that

\section{Nur Syafiqah Muhammed ${ }^{1 \mathrm{a}}$, Nurulfarhana Hussin ${ }^{16 \S}$ \\ Lim Aik Siang ${ }^{1 \mathrm{c}}$, Mohd Anuar Jonet ${ }^{2 \mathrm{~d}}$, Shaza Eva Mohamad ${ }^{3 \mathrm{e}}$, Haryati Jamaluddin ${ }^{1 \mathrm{f}}$}

(a)

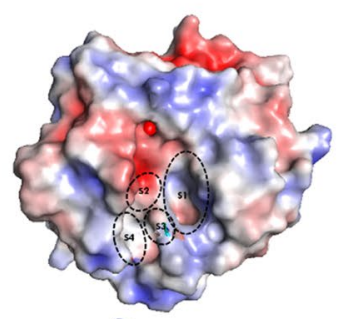

(d)

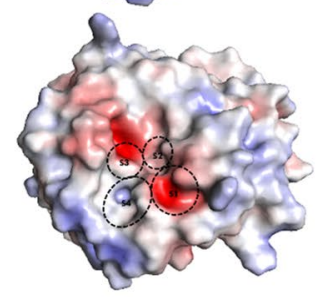

(g)

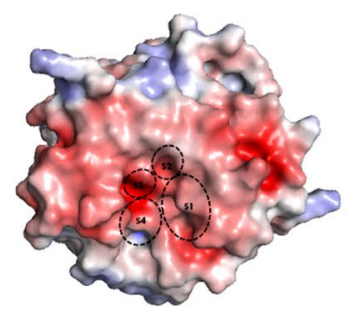

(b)

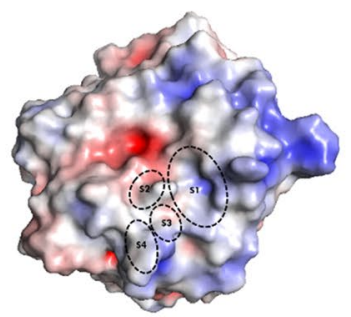

(e)

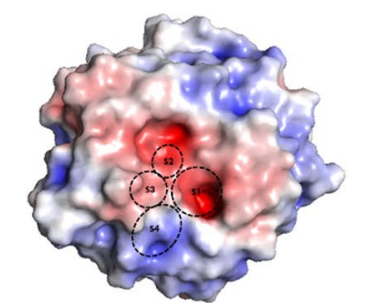

(h)

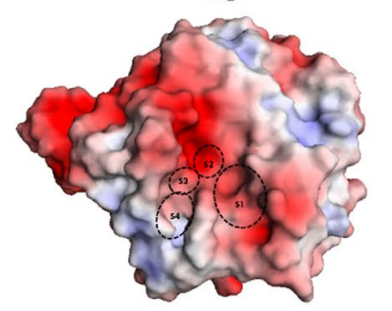

(c)

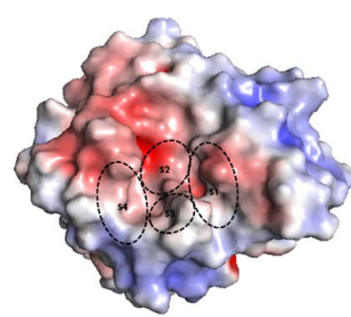

(f)

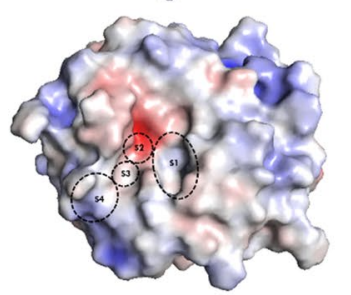

(i)

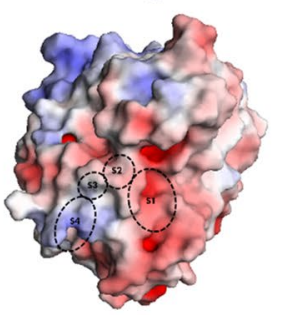

Fig. 13 Molecular electrostatic surface potentials of subtilisin-like serine proteases: a SPSFQ, b Keratin degrading -5WSL, c Fibrinolytic-5GL8, d Cuticle degrading-3F7M, e Cuticle degrading-3F7O, f Proteinase K-1IC6, g Collagen degrading-Destructin, h Collagen
degrading-3VV3, i extracellular matrix degrading-3TI9. The neutral, positive and negative charged electrostatic surfaces are coloured white, blue and red, respectively. The approximate location of substrate binding cleft; S1, S2, S3, S4 are indicated (color figure online) 

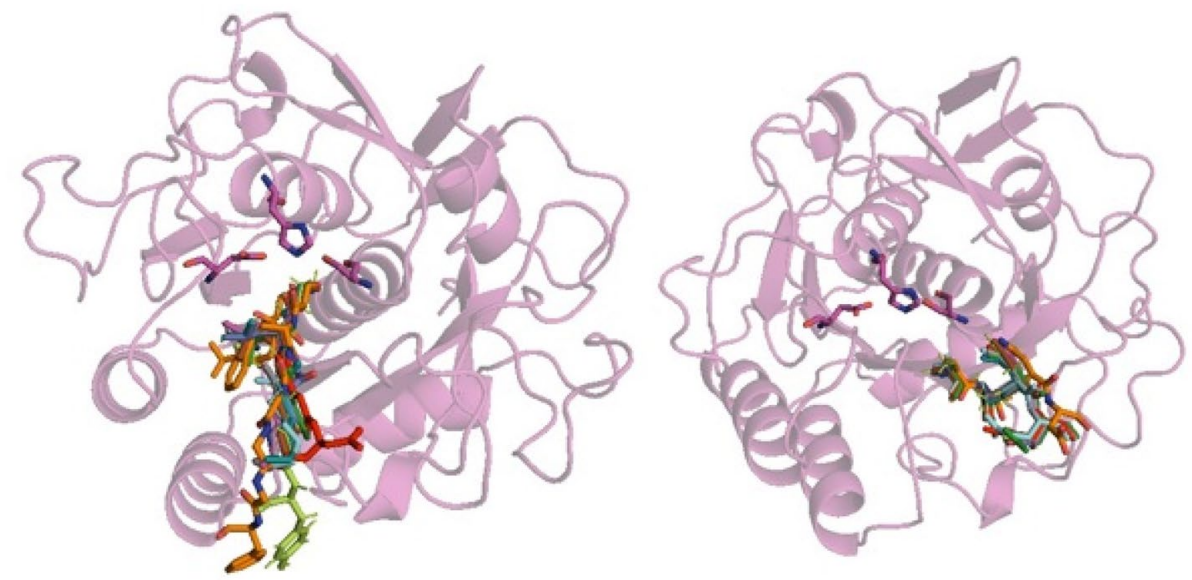

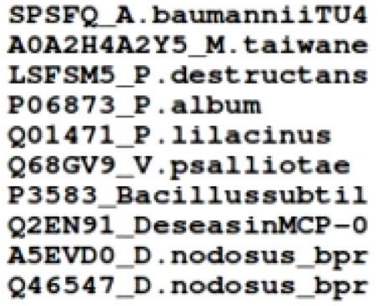

Fig. 14 S1 substrate binding pocket of SPSFQ with subtilisin-like serine proteases from different organisms: Keratinase from Meiothermus taiwanensis $\mathrm{Wr}-220$ (A0A2H4A2Y5); Destructin-1 from Pseudogymnoascus destructans (LSFSM5); Proteinase K from Parengyodontium album (P06873); cuticle-degrading proteases from Paecilomyces lilacinus, PL646 (Q01471) and Verticillium psalliotae, Ver112 (Q68GV9); fibrin-degrading nattokinase from Bacillus sub-

exhibited conformational flexibility at elevated temperatures in the substrate-binding region, thus enhancing the substrate affinity and catalytic efficiency of these enzymes [54, 77, 81]. However, this is not observed in SPSFQ which is categorized as a mesophilic protease as it showed optimum catalytic activity at temperatures of not more than $40{ }^{\circ} \mathrm{C}$. Highly electro-negative charge at the substrate-binding cleft of collagenolytic proteases from deep-sea bacterium Pseudoalteromonas sp. and psychrophilic fungus Pseudogymnoascus destructans contributed to the electrostatic attraction force with positively charged collagen substrate [75, 82]. In contrast, fungus-derived Proteinase $\mathrm{K}$ showed an overall more neutral charge on the substrate-binding cleft (Fig. 13f), yet was still able to degrade cuticle and collagen substrates at a similar degree to cuticle degrading protease, Ver112 [77]. The presence of acidic residues enhances the character of the S1 pocket to be more electro-negative hence increasing the flexibility and affinity of a protease to accommodate more complex substrates to catalyze $[54,75]$. This observation may explain why SPSFQ showed less catalytic efficiency towards complex substrates such as collagen and fibrin tilis (P3583); collagen-degrading Deseasin from marine Pseudoalteromonas $s p$ (Q2EN91); extracellular matrix-degrading proteases from Dichelobacter nodosus (A5EVD0 and Q46547). The regions of amino acids with black background and white foreground are completely conserved. The dotted frame in red indicates amino acids that are involved in the formation of S1 site (color figure online)

compared to the simpler forms of proteinaceous substrates such as casein and gelatin (denatured collagen). Substrate specificity and promiscuity often observed in proteases may be contributed by a combination of electrostatic charge, flexibility, and shape complementarity of the substrate-binding cleft [83].

\section{Conclusion}

Results from this study showed that SPSFQ shares a very high amino acid sequence identity with extracellular proteases from clinically relevant strains of Acinetobacter baumannii and Klebsiella pneumoniae. SPSFQ may be part of the proteolytic secretome of Acinetobacter baumannii that contributes to the physiological health of the bacteria by providing peptidic nutrients through hydrolysis of protein substrates. This is further reinforced by the substrate specificity study which showed that SPSFQ was able to degrade a variety of tissue-associated protein substrates. Whether the activity of this enzyme contributes to the virulence of 
pathogenic strains of the bacteria is still unknown however it warrants further investigation of SPSFQ related proteases in these clinical strains. In terms of commercial value, SPSFQ showed that it has favorable properties such as stable at alkaline $\mathrm{pH}$ and stable in the presence of surfactants, indicating that SPSFQ has the potential to be used as a proteolytic enzyme in detergent. SPSFQ showed varying degrees of promiscuity towards different protein substrates that may be attributed to the physico-chemical landscape of the enzyme's substrate binding site.

Acknowledgements This work was supported by the Science Fund from the Ministry of Science, Technology, and Innovation Malaysia (MOSTI) [Grant number 4S083].

\section{Declaration}

Conflict of interest All the authors declare that they have no conflict of interest.

\section{References}

1. Baumann P (1968) Isolation of Acinetobacter from soil and water. J Bacteriol 96(1):39-42. https://doi.org/10.1128/JB.96.1.39-42. 1968

2. Peleg AY, Seifert H, Paterson DL (2008) Acinetobacter baumannii: emergence of a successful pathogen. Clin Microbiol Rev 21(3):538-582. https://doi.org/10.1128/CMR.00058-07

3. Askari N, Momtaz H, Tajbakhsh E (2020) Prevalence and phenotypic pattern of antibiotic resistance of Acinetobacter baumannii isolated from different types of raw meat samples in Isfahan. Iran Vet Med Sci 6(1):147-153. https://doi.org/10.1002/vms3.199

4. Berlau J, Aucken H, Houang E, Pitt T (1999) Isolation of Acinetobacter spp including $A$. baumannii from vegetables: implications for hospital-acquired infections. J Hosp Infect 42(3):201-204. https://doi.org/10.1053/jhin.1999.0602

5. Farouk F, El Shimy R, Abdel-Motaleb A, Essam S, Azzazy HM (2020) Detection of Acinetobacter baumannii in fresh produce using modified magnetic nanoparticles and PCR. Anal Biochem. https://doi.org/10.1016/j.ab.2020.113890

6. Dijkshoorn L, Van Aken E, Shunburne L, Van Der Reijden T, Bernards A, Nemec A, Towner K (2005) Prevalence of Acinetobacter baumannii and other Acinetobacter spp. in faecal samples from non-hospitalised individuals. Clin Microbiol Infect 11(4):329-332

7. Seifert H, Baginski R, Schulze A, Pulverer G (1993) The distribution of Acinetobacter species in clinical culture materials. Z Bakteriol 279(4):544-552. https://doi.org/10.1016/s0934-8840(11) 80427-5

8. Barbier F, Timsit J-F (2020) Risk stratification for multidrugresistant bacteria in patients with skin and soft tissue infection. Curr Opin Infect Dis 33(2):137-145. https://doi.org/10.1097/ QCO.0000000000000642

9. Guerrero DM, Perez F, Conger NG, Solomkin JS, Adams MD, Rather PN, Bonomo RA (2010) Acinetobacter baumannii-associated skin and soft tissue infections: recognizing a broadening spectrum of disease. Surg Infect 11(1):49-57. https://doi.org/10. 1089/sur.2009.022

10. Motbainor H, Bereded F, Mulu W (2020) Multi-drug resistance of blood stream, urinary tract and surgical site nosocomial infections of Acinetobacter baumannii and Pseudomonas aeruginosa among patients hospitalized at Felegehiwot referral hospital, Northwest Ethiopia: a cross-sectional study. BMC Infect Dis 20(1):92. https://doi.org/10.1186/s12879-020-4811-8

11. Ballouz T, Aridi J, Afif C, Irani J, Lakis C, Nasreddine R, Azar E (2017) Risk factors, clinical presentation, and outcome of Acinetobacter baumannii bacteremia. Front Cell Infect Microbiol 7:156. https://doi.org/10.3389/fcimb.2017.00156

12. Dijkshoorn L, Nemec A, Seifert H (2007) An increasing threat in hospitals: multidrug-resistant Acinetobacter baumannii. Nat Rev Microbiol 5(12):939-951. https://doi.org/10.1038/nrmic ro1789

13. Khan HA, Baig FK, Mehboob R (2017) Nosocomial infections: epidemiology, prevention, control and surveillance. Asian Pac J Trop Biomed 7(5):478-482. https://doi.org/10.1016/j.apjtb.2017. 01.019

14. Johnson EN, Burns TC, Hayda RA, Hospenthal DR, Murray CK (2007) Infectious complications of open type III tibial fractures among combat casualties. Clin Infect Dis 45(4):409-415. https:// doi.org/10.1086/520029

15. Hamidian M, Nigro SJ (2019) Emergence, molecular mechanisms and global spread of carbapenem-resistant Acinetobacter baumannii. Microb Genom. https://doi.org/10.1099/mgen.0.000306

16. Ward O (2011) Proteases. Comprehens Biotechnol. https://doi. org/10.1016/B978-0-444-64046-8.00187-7

17. Bryan PN (2002) Prodomains and protein folding catalysis. Chem Rev 102(12):4805-4816. https://doi.org/10.1021/cr010190b

18. Eder J, Fersht AR (1995) Pro-sequence-assisted protein folding. Mol Microbiol 16(4):609-614. https://doi.org/10.1111/j.13652958.1995.tb02423.x

19. Vévodová J, Gamble M, Künze G, Ariza A, Dodson E, Jones DD, Wilson KS (2010) Crystal structure of an intracellular Subtilisin reveals novel structural features unique to this Subtilisin family. Structure 18(6):744-755. https://doi.org/10.1016/j.str.2010.03.008

20. Gamble M, Künze G, Dodson EJ, Wilson KS, Jones DD (2011) Regulation of an intracellular subtilisin protease activity by a short propeptide sequence through an original combined dual mechanism. Proc Natl Acad Sci 108(9):3536. https://doi.org/10.1073/ pnas. 1014229108

21. Cudic M, Fields GB (2009) Extracellular proteases as targets for drug development. Curr Protein Pept Sci 10(4):297-307. https:// doi.org/10.2174/138920309788922207

22. Culp E, Wright GD (2017) Bacterial proteases, untapped antimicrobial drug targets. J Antibiot 70(4):366-377. https://doi.org/10. 1038/ja.2016.138

23. Morris FC, Dexter C, Kostoulias X, Uddin MI, Peleg AY (2019) The mechanisms of disease caused by Acinetobacter baumannii. Front Microbiol 10:1601-1601. https://doi.org/10.3389/fmicb. 2019.01601

24. Weber BS, Kinsella RL, Harding CM, Feldman MF (2017) The secrets of Acinetobacter secretion. Trends Microbiol 25(7):532545. https://doi.org/10.1016/j.tim.2017.01.005

25. Bitrian M, Solari CM, González RH, Nudel CB (2012) Identification of virulence markers in clinically relevant strains of Acinetobacter genospecies. Int Microbiol 15(2):79-88. https://doi.org/10. 2436/20.1501.01.161

26. Haurat MF, Scott NE, Di Venanzio G, Lopez J, Pluvinage B, Boraston A, Ferracane MJ, Feldman MF (2020) The glycoprotease CpaA secreted by medically relevant Acinetobacter species targets multiple O-linked host glycoproteins. Microbiology. https://doi.org/10.1101/2020.07.22.216978

27. King LB, Pangburn MK, McDaniel LS (2013) Serine protease $\mathrm{PKF}$ of Acinetobacter baumannii results in serum resistance and suppression of biofilm formation. J Infect Dis 207(7):1128-1134. https://doi.org/10.1093/infdis/jis939

28. Kinsella RL, Lopez J, Palmer LD, Salinas ND, Skaar EP, Tolia NH, Feldman MF (2017) Defining the interaction of the protease $\mathrm{CpaA}$ with its type II secretion chaperone $\mathrm{CpaB}$ and 
its contribution to virulence in Acinetobacter species. J Biol Chem 292(48):19628-19638. https://doi.org/10.1074/jbc.M117. 808394

29. Tilley D, Law R, Warren S, Samis JA, Kumar A (2014) CpaA a novel protease from Acinetobacter baumannii clinical isolates deregulates blood coagulation. FEMS Microbiol Lett 356(1):5361. https://doi.org/10.1111/1574-6968.12496

30. Waack U, Warnock M, Yee A, Huttinger Z, Smith S, Kumar A, Deroux A, Ginsburg D, Mobley HL, Lawrence DA (2018) CpaA is a glycan-specific adamalysin-like protease secreted by Acinetobacter baumannii that inactivates coagulation factor XII. MBio. https://doi.org/10.1128/mBio.01606-18

31. Salwan R, Sharma V, Pal M, Kasana RC, Yadav SK, Gulati A (2018) Heterologous expression and structure-function relationship of low-temperature and alkaline active protease from Acinetobacter sp. IHB B 5011 (MN12). Int J Biol Macromol 107:567574. https://doi.org/10.1016/j.ijbiomac.2017.09.025

32. Zhang R-X, Gong J-S, Zhang D-D, Su C, Hou Y-S, Li H, Shi J-S, $\mathrm{Xu}$ Z-H (2016) A metallo-keratinase from a newly isolated Acinetobacter sp R-1 with low collagenase activity and its biotechnological application potential in leather industry. Bioprocess Biosyst Eng 39(1):193-204. https://doi.org/10.1007/s00449-015-1503-7

33. Krishnan R (2016) Molecular cloning and characterization of a new fibrinolytic enzyme from Acinetobacter baumannii TU04. Universiti Teknologi Malaysia, Johor

34. Sayuti SAM (2012) Isolation, screening and characterization of fibrinolytic enzyme producing bacteria from tapai. Universiti Teknologi Malaysia, Johor

35. Altschul SF, Gish W, Miller W, Myers EW, Lipman DJ (1990) Basic local alignment search tool. J Mol Biol 215(3):403-410. https://doi.org/10.1016/s0022-2836(05)80360-2

36. Ferre F, Clote $\mathrm{P}$ (2005) Disulfide connectivity prediction using secondary structure information and diresidue frequencies. Bioinformatics 21(10):2336-2346. https://doi.org/10.1093/bioinforma tics/bti328

37. Gasteiger E, Gattiker A, Hoogland C, Ivanyi I, Appel RD, Bairoch A (2003) ExPASy: the proteomics server for in-depth protein knowledge and analysis. Nucleic Acids Res 31(13):3784-3788. https://doi.org/10.1385/1-59259-890-0:571

38. Tamura K, Peterson D, Peterson N, Stecher G, Nei M, Kumar S (2011) MEGA5: molecular evolutionary genetics analysis using maximum likelihood, evolutionary distance, and maximum parsimony methods. Mol Biol Evol 28(10):2731-2739. https://doi. org $/ 10.1093 / \mathrm{molbev} / \mathrm{msr} 121$

39. Gasteiger E, Hoogland C, Gattiker A, Wilkins MR, Appel RD, Bairoch A (2005) Protein identification and analysis tools on the ExPASy server. In: The proteomics protocols handbook. Springer, New York, pp 571-607

40. Laskowski RA, MacArthur MW, Moss DS, Thornton JM (1993) PROCHECK: a program to check the stereochemical quality of protein structures. J Appl Crystallogr 26(2):283-291. https://doi. org/10.1107/S0021889892009944

41. Webb B, Sali A (2016) Comparative protein structure modeling using MODELLER. Current protocols in protein science 86 (1):2.9. 1-2.9. 37. doi:https://doi.org/10.1002/cpbi.3

42. Wu W-L, Chen M-Y, Tu I-F, Lin Y-C, EswarKumar N, Chen M-Y, Ho M-C, Wu S-H (2017) The discovery of novel heatstable keratinases from Meiothermus taiwanensis WR-220 and other extremophiles. Sci Rep 7(1):4658. https://doi.org/10.1038/ s41598-017-04723-4

43. Schrodinger L (2010) The PyMOL Molecular Graphics System, Version 2.4.0.

44. Iacono M, Villa L, Fortini D, Bordoni R, Imperi F, Bonnal RJ, Sicheritz-Ponten T, De Bellis G, Visca P, Cassone A, Carattoli A (2008) Whole-genome pyrosequencing of an epidemic multidrug-resistant Acinetobacter baumannii strain belonging to the European clone II group. Antimicrob Agents Chemother 52(7):2616-2625. https://doi.org/10.1128/aac.01643-07

45. Rawlings ND, Barrett AJ, Bateman A (2009) MEROPS: the peptidase database. Nucleic Acids Res 38(suppl 1):D227-D233. https://doi.org/10.1093/nar/gkp971

46. Baker D, Silen JL, Agard DA (1992) Protease pro region required for folding is a potent inhibitor of the mature enzyme. Proteins Struct Funct Bioinf 12(4):339-344. https://doi.org/10.1002/prot. 340120406

47. Huang H-W, Chen W-C, Wu C-Y, Yu H-C, Lin W-Y, Chen S-T, Wang K-T (1997) Kinetic studies of the inhibitory effects of propeptides subtilisin BPN'and Carlsberg to bacterial serine proteases. Protein Eng 10(10):1227-1233. https://doi.org/10.1093/ protein/10.10.1227

48. Li Y, Hu Z, Jordan F, Inouye M (1995) Functional analysis of the propeptide of subtilisin $\mathrm{E}$ as an intramolecular chaperone for protein folding. Refolding and inhibitory abilities of propeptide mutants. J Biol Chem 270(42):25127-25132. https://doi.org/10. 1074/jbc.270.42.25127

49. Yabuta Y, Takagi H, Inouye M, Shinde U (2001) Folding pathway mediated by an intramolecular chaperone propeptide release modulates activation precision of pro-subtilisin. J Biol Chem 276(48):44427-44434. https://doi.org/10.1074/jbc.M107573200

50. Shinde U, Liu J, Inouye M (1997) Protein memory through altered folding mediated by intramolecular chaperones. Nature 389(6650):520. https://doi.org/10.1038/39097

51. Siezen RJ, Leunissen JA (1997) Subtilases: the superfamily of subtilisin-like serine proteases. Protein Sci 6(3):501-523. https:// doi.org/10.1002/pro.5560060301

52. Barrett AJ, Woessner JF, Rawlings ND (2012) Handbook of proteolytic enzymes, vol 1. Elsevier

53. Muller A, Hinrichs W, Wolf WM, Saenger W (1994) Crystal structure of calcium-free proteinase $\mathrm{K}$ at 1.5-A resolution. J Biol Chem 269(37):23108-23111. https://doi.org/10.2210/pdb2pkc/ $\mathrm{pdb}$

54. Liu S-Q, Liang L-M, Yan T, Yang L-Q, Ji X-L, Yang J-K, Fu Y-X, Zhang K-Q (2011) Structural and dynamic basis of serine proteases from nematophagous fungi for cuticle degradation. In: Stoytcheva M (ed) Pesticides in the modern world-pests control and pesticides exposure and toxicity assessment. InTech, New York, pp 333-376

55. Laskowski RA, MacArthur MW, Thornton JM (2002) PROCHECK: validation of protein structure coordinates. Kluwer Academic Publishers, Netherlands

56. Bowie JU, Lüthy R, Eisenberg D (1991) A method to identify protein sequences that fold into a known three-dimensional structure. Science 253(5016):164-170. https://doi.org/10.1126/science. 1853201

57. Lüthy R, Bowie JU, Eisenberg D (1992) Assessment of protein models with three-dimensional profiles. Nature 356(6364):83-85. https://doi.org/10.1038/356083a0

58. Colovos C, Yeates TO (1993) Verification of protein structures: patterns of nonbonded atomic interactions. Protein Sci 2(9):15111519. https://doi.org/10.1002/pro.5560020916

59. Murzin AG, Brenner SE, Hubbard T, Chothia C (1995) SCOP: a structural classification of proteins database for the investigation of sequences and structures. J Mol Biol 247(4):536-540. https:// doi.org/10.1016/S0022-2836(05)80134-2

60. Sillitoe I, Lewis TE, Cuff A, Das S, Ashford P, Dawson NL, Furnham N, Laskowski RA, Lee D, Lees JG, Lehtinen S, Studer RA, Thornton J, Orengo CA (2015) CATH: comprehensive structural and functional annotations for genome sequences. Nucleic Acids Res 43(D1):D376-D381. https://doi.org/10.1093/nar/gku947

61. Shinde U, Fu X, Inouye M (1999) A pathway for conformational diversity in proteins mediated by intramolecular chaperones. $\mathrm{J}$ Biol Chem 274(22):15615-15621 
62. Kristjánsson MM, Magnússon ÓT, Gudmundsson HM, Alfredsson GÁ, Matsuzawa H (1999) Properties of a subtilisin-like proteinase from a psychrotrophic Vibrio species. FEBS J 260(3):752-760. https://doi.org/10.1046/j.1432-1327.1999.00205.x

63. Takagi H, Takahashi T, Momose H, Inouye M, Maeda Y, Matsuzawa H, Ohta T (1990) Enhancement of the thermostability of subtilisin $\mathrm{E}$ by introduction of a disulfide bond engineered on the basis of structural comparison with a thermophilic serine protease. J Biol Chem 265(12):6874-6878

64. Park JY, Kim S, Kim S-M, Cha SH, Lim S-K, Kim J (2011) Complete genome sequence of multidrug-resistant Acinetobacter baumannii strain 1656-2, which forms sturdy biofilm. J Bacteriol 193(22):6393-6394. https://doi.org/10.1128/jb.06109-11

65. Russo A, Giuliano S, Ceccarelli G, Alessandri F, Giordano A, Brunetti G, Venditti M (2018) Comparison of septic shock due to multidrug-resistant Acinetobacter baumannii or Klebsiella pneumoniae carbapenemase-producing $K$ pneumoniae in intensive care unit patients. Antimicrob Agents Chemother 62(6): $02562-\mathrm{e} 12517$

66. Săndulescu O, Stoica M, Berciu I, Streinu-Cercel A, Preoțescu L, Streinu-Cercel A (2014) Dual infection with Acinetobacter baumannii and Klebsiella pneumoniae in a patient with multiple comorbidities—case presentation. BMC Infect Dis 14(7):26. https://doi.org/10.1186/1471-2334-14-s7-p26

67. O’Donoghue AJ, Knudsen GM, Beekman C, Perry JA, Johnson AD, DeRisi JL, Craik CS, Bennett RJ (2015) Destructin-1 is a collagen-degrading endopeptidase secreted by Pseudogymnoascus destructans, the causative agent of white-nose syndrome. Proc Natl Acad Sci 112:7478-7483

68. Arnorsdottir J, Smáradóttir RB, Magnusson OT, Thorbjarnardóttir SH, Eggertsson G, Kristjánsson MM (2002) Characterization of a cloned subtilisin-like serine proteinase from a psychrotrophic Vibrio species. FEBS J 269(22):5536-5546. https://doi.org/10. 1046/j.1432-1033.2002.03259.x

69. Terada I, Kwon ST, Miyata Y, Matsuzawa H, Ohta T (1990) Unique precursor structure of an extracellular protease, aqualysin I, with NH2- and $\mathrm{COOH}$-terminal pro-sequences and its processing in Escherichia coli. J Biol Chem 265(12):6576-6581

70. Pannkuk EL, Risch TS, Savary BJ (2015) Isolation and identification of an extracellular subtilisin-like serine protease secreted by the bat pathogen Pseudogymnoascus destructans. PLoS ONE 10(3):e0120508. https://doi.org/10.1371/journal.pone.0120508

71. Thebti W, Riahi Y, Belhadj O (2016) Purification and characterization of a new thermostable, Haloalkaline, solvent stable, and detergent compatible serine protease from Geobacillus toebii strain LBT 77. BioMed Res Int. https://doi.org/10.1155/2016/ 9178962

72. Gold AM, Fahrney D (1964) Sulfonyl fluorides as inhibitors of esterases. II. Formation and reactions of phenylmethanesulfonyl $\alpha$-chymotrypsin. Biochemistry 3(6):783-791. https://doi.org/10. 1021/bi00894a009

73. Maurer KH (2004) Detergent proteases. Curr Opin Biotechnol 15(4):330-334. https://doi.org/10.1016/j.copbio.2004.06.005

74. Valls C, Pujadas G, Garcia-Vallve S, Mulero M (2011) Characterization of the protease activity of detergents laboratory practicals for studying the protease profile and activity of various commercial detergents. Biochem Mol Biol Educ 39(4):280-290. https:// doi.org/10.1002/bmb.20488

75. Ran LY, Su HN, Zhao GY, Gao X, Zhou MY, Wang P, Zhao HL, Xie BB, Zhang XY, Chen XL (2013) Structural and mechanistic insights into collagen degradation by a bacterial collagenolytic serine protease in the subtilisin family. Mol Microbiol 90(5):9971010. https://doi.org/10.1111/mmi.12412

76. Liang L, Liu S, Yang J, Meng Z, Lei L, Zhang K (2011) Comparison of homology models and crystal structures of cuticledegrading proteases from nematophagous fungi: structural basis of nematicidal activity. FASEB J 25(6):1894-1902. https://doi. org/10.1096/fj.10-175653

77. Liang L, Meng Z, Ye F, Yang J, Liu S, Sun Y, Guo Y, Mi Q, Huang X, Zou C, Rao Z, Lou Z, Zhang K-q (2010) The crystal structures of two cuticle-degrading proteases from nematophagous fungi and their contribution to infection against nematodes. FASEB J 24:1391-1400. https://doi.org/10.1096/fj.09-136408

78. Wong W, Wijeyewickrema LC, Kennan RM, Reeve SB, Steer DL, Reboul C, Smith AI, Pike RN, Rood JI, Whisstock JC (2011) S1 pocket of a bacterially derived subtilisin-like protease underpins effective tissue destruction. J Biol Chem 286(49):42180-42187. https://doi.org/10.1074/jbc.M111.298711

79. Bryan PN (2000) Protein engineering of subtilisin. Biochim Biophys Acta 1543(2):203-222. https://doi.org/10.1016/s01674838(00)00235-1

80. Perona JJ, Craik CS (1995) Structural basis of substrate specificity in the serine proteases. Protein Sci 4:337-360. https://doi.org/10. 1002/pro.5560040301

81. Tao Y, Rao Z-H, Liu S-Q (2010) Insight derived from molecular dynamics simulation into substrate-induced changes in protein motions of Proteinase K. J Biomol Struct Dyn 28(2):143-157. https://doi.org/10.1080/073911010010524953

82. O'Donoghue AJ, Knudsen GM, Beekman C, Perry JA, Johnson AD, DeRisi JL, Craik CS, Bennett RJ (2015) Destructin-1 is a collagen-degrading endopeptidase secreted by Pseudogymnoascus destructans, the causative agent of white-nose syndrome. Proc Natl Acad Sci U S A 112(24):7478-7483. https://doi.org/10.1073/ pnas. 1507082112

83. Waldner BJ, Kraml J, Kahler U, Spinn A, Schauperl M, Podewitz M, Fuchs JE, Cruciani G, Liedl KR (2018) Electrostatic recognition in substrate binding to serine proteases. J Mol Recognit 31(10):e2727. https://doi.org/10.1002/jmr.2727

84. Gouet P, Courcelle E, Stuart DI, Métoz F (1999) ESPript: analysis of multiple sequence alignments in PostScript. Bioinformatics (Oxford, England) 15(4):305-308. https://doi.org/10.1093/bioin formatics/15.4.305

Publisher's Note Springer Nature remains neutral with regard to jurisdictional claims in published maps and institutional affiliations. 